\title{
Can medical products be developed on a non-profit basis? Exploring product development partnerships for neglected diseases
}

\author{
V. Muñoz ${ }^{1, *}$, F. Visentin ${ }^{1}$, D. Foray ${ }^{1}$ and P. Gaulé ${ }^{2}$ \\ ${ }^{I}$ Chair of Economics and Management of Innovation, École Polytechnique Fédérale de Lausanne, \\ ODY 101 A, Station 5, CH-1015 Lausanne, Switzerland \\ ${ }^{2}$ CERGE-EI, Prague, Czech Republic \\ *Corresponding author.Email: viviana.munoz@epfl.ch.
}

\begin{abstract}
Reliance on market forces can lead to underinvestment in social welfare enhancing innovation. The lack of new medical products in the area of neglected diseases is a case in point. R\&D for neglected diseases has increased with new funding and collaborations taking place mainly through product development partnerships (PDPs). PDPs are self-governing, private non-profit R\&D organizations. In contrast to push and pull instruments designed to address private-sector R\&D underinvestment, PDPs have emerged voluntarily to address this public health challenge. In this study we examine how non-profit $R \& D$ collaboration for neglected diseases takes place through PDPs. We find that PDPs act as 'system integrators' that leverage the resources and capabilities of a network of public, philanthropic and private-sector partners. This paper contributes to an understanding of R\&D in a non-profit context and highlights the importance of collaboration and nonmarket institutions for promoting innovation where market failures occur.
\end{abstract}

Keywords: R\&D collaboration; non-profit; innovation; neglected diseases.

\section{Introduction}

Over a billion people are affected by diseases that have a large burden in developing countries, but no or small burden in the developed world (World Health Organization 2010). Historically, government public health programmes and the pharmaceutical industry have neglected these poverty-related diseases. Very few new medical products (drugs, vaccines and other biological products, diagnostics and vector control products) are developed for their prevention and treatment. Pharmaceutical firms, without market incentives to spur their commercial interests, are reluctant to engage independently in these endeavours. As a result, they pass up opportunities for socially valuable innovation.
Economists have proposed a range of economic instruments to incentivize firm-level R\&D in neglected diseases. Push mechanisms that aim to bring down firms' costs of $\mathrm{R} \& \mathrm{D}$, such as grants, tax credits and loans are more broadly used by policy-makers. Pull mechanisms, on the other hand, such as milestone or end prizes, aim to increase market attractiveness by lowering the risk of $\mathrm{R} \& \mathrm{D}$ and assuring revenue for the outputs.

Meanwhile, a rising number of self-governing private non-profit organizations have emerged to catalyse R\&D for neglected diseases. Product development partnerships (PDPs) have produced various new diagnostics and therapies in the form of reformulated or repurposed versions of existing drugs, vaccines and biological 
products. They have also built significant R\&D project portfolios with several novel vaccines and drug candidates in the pipeline, including new chemical entities (NCE). Most PDPs do not undertake any in-house R\&D activities: instead they operate through external collaboration. PDPs mobilize funding from philanthropic and public entities and form partnerships with a number of public and private institutions (including academia and public research institutes, pharmaceutical, biotechnology and other private for-profit firms, such as contract research organizations) to implement $R \& D$ projects.

This openness of PDPs to external R\&D collaboration can appear to mirror a similar trend in the pharmaceutical and biotechnology industry (Juliano 2013). However, the motivation for PDPs to pursue R\&D collaboration is clearly associated with their non-profit mission. Large pharmaceutical firms are increasingly sourcing their $\mathrm{R} \& \mathrm{D}$ portfolios by in-licensing external $\mathrm{R} \& \mathrm{D}$ projects and through mergers and acquisitions to raise growth and revenue prospects (Schuhmacher et al. 2013). In contrast, the common goal of PDPs is to build R\&D portfolios to develop products that address unmet health needs. This means that the final product must be affordable and accessible to patients. In this context, partners involved in PDP-led $R \& D$ projects have to operate within the confines of the PDP mission. The concept of 'partnership' implies a commitment to a common goal through the joint provision of complementary resources and expertise, and the joint sharing of the risks involved (Ridley 2001).

This research is informed by a literature review and indepth interviews with the staff of PDPs. Previous literature has described the role of PDPs in the neglected disease landscape (Moran 2005b; Grace 2006, 2010; Chataway et al. 2007, 2010; Moran et al. 2010). While building on this literature, we further explain the operation of PDPs, identify their core capabilities, provide an update of PDP outputs, and analyse the variety among PDPs and the constraints of the PDP approach.

This study is divided into seven sections. Following the introduction, Section 2 presents the problem of insufficient innovation for neglected diseases. Section 3 then describes the economic instruments that are designed to stimulate innovation in neglected diseases. Section 4 explores how PDPs access and leverage external resources and capabilities through R\&D collaborations. Section 5 explains the variety within the PDP landscape. Section 6 discusses the limitations of the PDP organizational form. Conclusions are drawn in Section 7.

\section{The shortfall of innovation for neglected diseases}

The expression 'neglected disease' indicates the problem of insufficient new medical products developed to address diseases that create a large burden in developing countries, but have little or no impact in the developed world. There is no single definition of a 'neglected disease'. The WHO defines 'neglected diseases' as a group of 17 diseases affecting more than 1 billion people worldwide that persist under conditions of poverty and are concentrated almost exclusively in impoverished populations in developing countries (World Health Organization 2010). ${ }^{1}$ In particular, infectious diseases account for 10 million deaths each year, of which more than $90 \%$ occur in developing countries (World Health Organization 2010). For the purposes of our study, we consider the WHO-listed diseases and also include three communicable diseases: TB, malaria and HIV/AIDS. ${ }^{2}$ These diseases are prevalent in developing countries and often co-exist with other neglected diseases. However, they differ from other 'neglected' diseases in that they may also be found in developed countries (e.g. TB and HIV/AIDS) and generally receive more financing for R\&D and delivery.

New medical products are essential for the prevention, control and elimination of disease. The current level of R\&D for new medical products targeting neglected diseases is negligible relative to the health burden of these diseases. The imbalance is evident if we consider: first, the amount of $R \& D$ investment for neglected diseases compared to the global $\mathrm{R} \& \mathrm{D}$ investment for all diseases and the health burden of neglected diseases; and secondly, the number of new medical products developed for neglected diseases compared to other diseases.

One study has found that global R\&D investments by the public, philanthropic and private sectors in neglected disease research in 2010 (approximately US $\$ 2.4$ billion) accounted for only $1 \%$ of overall health R\&D investments (US\$240 billion) (Røttingen et al. 2013). Funding for neglected diseases has slightly increased from an estimated US\$2.8 billion in 2005 (Global Forum for Health Research 2008) to US $\$ 3.045$ billion in 2011 (Policy Cures 2012). The largest funders are public donors, with a total of US\$1.9 billion in 2011, followed by philanthropic donors, with a total of US\$525.1 million in 2011 (Policy Cures 2012).

The small number of new medical products for neglected diseases, as compared to other diseases, is an indication of the persistent gap in innovation within this area. One landmark study found that in the period 1975-99, 1,393 new drugs (excluding vaccines) were made available to the public. However, only 16 of these were intended for neglected diseases (Troullier et al. 2002). A recent study finds that of the 850 new therapeutic products (NCE, new indications, new formulations, fixed-dose combinations, and vaccines and biologicals) registered in the period 2000 11 , only $37(4 \%)$ were indicated for neglected diseases, comprising 25 products with a new indication or formulation, and eight vaccines or biological products. Of those 25 products, only four were NCE. Only $1 \%$ of all registered 
clinical trials were for neglected diseases (Pedrique et al. 2013).

Generally firms invest in $R \& D$ with the expectation that the revenues generated from the sales of new medical products will increase as a result. They finance $R \& D$ from their own resources (profits), as well as from public support instruments, such as tax breaks and grants. Nonetheless, firms generally tend to invest less than the socially optimal levels of R\&D. The reasons include: high risks and costs, problems of R\&D financing and incomplete appropriability of returns to R\&D (Nelson 1959; Hall and Lener 2010). To address the appropriability problem, firms can seek legal protection for their inventions through government-granted patents that give the firms time-limited monopoly control (i.e. manufacture, use and sales) over the product. Patents support a firm's pricing strategy, aimed at setting a price as profitable as the buyer (there can be several possible buyers, such as government health authorities, insurers, prescribers/pharmacists or patients out-of-pocket) is willing to pay. Use of patent-protected inventions normally requires authorization by the patent holder. Only after the patent protection expires, generally a 20 -year period, can any other firm produce and market a generic version of the product. This competition helps to bring down the product price.

The pharmaceutical industry has historically invested very little in $R \& D$ for new medical products within the area of neglected diseases. This is to be expected, as the market for neglected diseases does not offer firms many opportunities for profit, despite the gross unmet needs for treatment. Accordingly, the economic barriers to $\mathrm{R} \& \mathrm{D}$ in neglected diseases by private firms can be described as follows (Webber and Kremer 2001):

- Commercial markets are small.

- Individual purchasing power is limited, even though the number of patients may be very large.

- High R\&D costs (estimated to be the same as for new medical products for other diseases) and the inherent risk in R\&D will not be covered by returns on investments.

Moreover, patents as an incentive for the appropriability of R\&D returns are not an effective mechanism to stimulate $R \& D$ in neglected diseases, given the absence of a profitable market, and may rather affect the availability of affordable medical products (World Health Organization 2006).

It can be assumed that the risks and costs of new product development for neglected disease R\&D may be the same as for other diseases. ${ }^{3}$ Medical product development is generally very costly, with a high risk of failure. However, precise data on the $R \& D$ costs of pharmaceutical firms are generally unavailable or undisclosed. This is a critical constraint for the adequate design of economic instruments and their employment to incentivize $R \& D$ in neglected as well as in other diseases. When firms do provide cost data, it is not specified how the R\&D costs are calculated, or what is included in the cost (Morgan et al. 2011). It is estimated that a drug in the form of NCE may take 13-5 years, from discovery to when it is available on the market. For vaccines, the full R\&D process may take 12 years. The levels of attrition (likelihood of project failure) can be close to $60 \%$, higher in the discovery stage. Published estimates of the R\&D costs diverge widely, with existing studies varying in methodologies, data sources, samples and time periods. For example, a recent study by health economists calculated that the net median R\&D cost may be in the range of US\$13-204 million, while existing estimates range from US\$161 million to US\$1.8 billion (Light and Warburton 2011).

There are also no concrete data on the overall extent of $\mathrm{R} \& \mathrm{D}$ investment in medical products by pharmaceutical firms. While R\&D costs have risen in the past two decades, revenues for pharmaceutical firms have increased six times faster, with net profits after taxes substantially higher than profits for all other Fortune 500 companies (Light and Lexchin 2012). At the same time, the overall rate of innovation in the pharmaceutical industry has been in decline. The number of total innovative new medical products approved has fallen since the 1990s, while many of those are 'me too' drugs, rather than new chemical (or molecular) entities, and are without significant therapeutic value.

\section{Economic instruments to stimulate innovation in neglected diseases}

In the last decades, various instruments have been designed, and some have been implemented to address the underinvestment problem illustrated above. With the aim of filling the gap between private and social returns to $\mathrm{R} \& \mathrm{D}$ in the field of neglected diseases, 'push' and 'pull' instruments have been explored by public and philanthropic sectors for financing and increasing R\&D efforts.

'Push' instruments aim to stimulate R\&D by reducing the costs of $\mathrm{R} \& \mathrm{D}$ for the industry. These include instruments that pay for inputs to $\mathrm{R} \& \mathrm{D}$, such as providing direct funding to research, particularly basic research (Toole 2002), but may also extend to applied research (grants to universities, government public research laboratories, or for joint projects with industry), R\&D tax breaks, direct grants for small firms, funding for clinical trials in developing countries, open innovation platforms, patent pools and related initiatives, fast track regulatory review (approvals), pre-competitive research platforms for sharing R\&D costs and regulatory harmonization. Some of the problems associated with pull instruments are that they may not provide sufficient incentive for $\mathrm{R} \& \mathrm{D}$ by themselves. Incentives between grantees and funders may be imperfectly aligned, and the instruments are vulnerable to politization/lobbying (Hegde and Sampat 2014). 
'Pull' instruments pay for the outputs of R\&D. The main barrier considered is insufficient market attractiveness, rather than the high cost of R\&D. Pull instruments aim to address the problem of a lack of commercial markets. They are designed to create demand for yet-tobe-developed products and effectively enlarge the market for medical products in neglected diseases. Pull instruments reward the output (new medical products developed) rather than pay for inputs to $R \& D$. There is limited practical experience with pull instruments for neglected diseases. ${ }^{4}$ One attractive feature of pull instruments is that they are less costly than other instruments, as they do not entail upfront payments. Money is spent only if milestones are reached or if new medical products are developed in accordance with pre-defined criteria. The specified criteria would be pre-set by the purchaser (i.e. government, philanthropic organization or international organization). The firm or other entity could then decide on the R\&D strategy to deploy in order to meet the criteria. Once the milestone is reached or the product is developed, the disbursement of the money committed would be made, and the purchaser could make the product available to patients at low or no cost. Examples of pull instruments include: prizes, funds for end-payments (such as the Health Impact Fund), funds that would allocate resources to any research organization, ${ }^{5}$ and advance market commitments (AMC).

A critical condition of the pull instrument is that the payment has to be sufficiently attractive to provide incentives to the participants in the scheme. In theory, an adequate size of the incentive may vary among participants. For private firms, it requires increasing the likelihood of returns to their R\&D investments (at best, brings profits, at minimum, no loss). For other types of organizations, such as non-profit PDPs, the size of the incentive required may be smaller. In the design of pull instruments, a crucial element is the amount of the commitments (including specifications, such as the doses to be purchased and purchase price) that would be required to provide a sufficiently strong incentive to create a market that would surpass the barrier to R\&D investment. Kremer (2001) foresaw that substantial industrial investment in neglected disease $R \& D$ would occur only if expected rates of return were broadly equivalent to those anticipated from $R \& D$ in conventional areas. However, without proper information on the actual costs of $\mathrm{R} \& \mathrm{D}$, public resources may be wasted. Robust data on the costs of $R \& D$ for new medical product development should inform these decisions. However, as discussed earlier, existing estimates for medical product innovation are unreliable.

A different means to spur medical innovation is via open models, based on collaboration. In the discovery phase, open models of innovation rely on collaboration, sharing of information among volunteers and open access to data. Two examples of these projects that have been studied are CSIR Team India Consortium's Open Source Drug
Discovery project and the Synaptic Leap's Schistosomiasis project (Årdal and Rottingen 2012).

Various pull and push mechanisms and alternative means for medical product innovation have been recently reviewed by an expert working group of the WHO (World Health Organization 2012b).

\section{Organizations to drive innovation in neglected diseases: PDPs}

Evidence suggests that collaboration in R\&D for neglected diseases is increasing. One study has found that there are approximately 348 organizations from the private and public sectors (academic/research institutions, biotechnology companies and other medium and small firms, such as contract research organizations, and large pharmaceutical companies) participating alone or in partnership with each other in the development of a combined pipeline of 374 drugs and vaccines for 23 neglected diseases (BioVentures for Global Health 2012). The majority of collaborations are reported to be taking place through PDPs, with a $40 \%$ share of participation in the total number of projects (Bio Ventures for Global Health 2012). Another study has found that for the 123 new medical products in development in the period 2000-11, public organizations were involved in 66 products $(54 \%)$, private industry in 28 products $(23 \%)$, and private non-profit organizations (including PDPs, charities, foundations and philanthropic institutions) in 19 products $(15 \%)$, with the remaining ten products $(8 \%)$ involving a mix of sponsors. All three NCE for neglected diseases were being sponsored by private non-profit organizations (Pedrique et al. 2013). It also appears that large pharmaceutical firms are increasingly interested in joining PDP projects more than in undertaking their own. The annual report by the International Federation of Pharmaceutical Manufacturers and Associations (IFPMA) for 2012 (IFPMA 2012), lists 132 R\&D projects for new medicines and vaccines (excluding HIV/AIDS) involving IFPMA member companies, of which 112 are projects with PDPs, and only $20(15 \%)$ projects are firm-only undertakings.

PDPs in the past 15 years have become part of the puzzle of how to close the innovation gap for neglected diseases. One study found that the PDP pipeline included 63 neglected disease drug projects (excluding vaccines, diagnostics and microbicides) under way at the end of 2004, including two new drugs at the registration stage and 18 new products in clinical trials, half of which had already reached phase III (Moran 2005a). However, new projects have been launched since the end of 2004, amplifying this trend (Bio Ventures for Global Health 2012). A full list and description of new products developed by PDPs is found in Appendix 2 at the end of this paper. 
Since the 1990s the number of PDPs has grown from one to 23 PDPs in 2014, which we have identified in our study. ${ }^{6}$ For purposes of our study, we define PDPs as selfgoverning, ${ }^{7}$ private, non-profit organizations that aim to develop new medical products in the area of neglected diseases. PDPs are not push or pull instruments for R\&D. As discussed in Section 3, push and pull instruments are policy instruments designed mainly to promote private investment in R\&D. ${ }^{8}$ In contrast, PDPs are R\&D organizations that have emerged to bring about innovations in an area where neither the private or public non-market institutions can, or are willing to, do the task alone (Chataway et al. 2010).

\subsection{History of PDPs}

Members of the global public health community (such as the World Health Organization, civil society organizations and doctors) initiated PDPs as a practical means to increase $R \& D$ for neglected diseases. However, it is not evident why a new organizational innovation in the form of PDPs was needed in the context of existing organizations in global public health governance. These include public research institutions, firms (biotechnology and big pharmaceutical firms), government agencies, international organizations such as the WHO, the World Bank, UNDP, UNESCO, UNICEF and UNITAID, civil society organizations and existing networks of research collaborations. We trace the origins of PDPs and identify the gaps in existing organizational structures to which PDPs are responding.

Some of the early PDPs were catalysed at the WHO through the Special Programme for Research and Training in Tropical Diseases (TDR) and the experience with partnerships it progressively forged in the 1980s1990s. ${ }^{9}$ Before the TDR, there was no international framework focused on coordinating research to support infectious disease control, particularly in the developing world (UNICEF et al. 2007). The role of TDR evolved in time, from a focus on strengthening research capability building in endemic countries to promoting international collaboration to increase R\&D for neglected diseases. Scientists engaged in the private sector had been participating in TDR committees, but the private sector was not formally engaged in the work of the TDR. In time, opportunities arose for product development in collaboration with the industry. However, it appeared to be too costly and complex for TDR to manage and implement, and it was outside of its mandate. With this in mind, the idea of creating independent, disease-focused organizations appeared as an avenue to speed up R\&D and the delivery of new medical products to meet health needs.

TDR has assisted in the creation various PDPs since $1999,{ }^{10}$ while other PDPs were created independently. ${ }^{11}$ Non-profit philanthropic foundations, such as the Rockefeller Foundation, have played an active role in cultivating PDPs. International humanitarian organizations also have played a key role (Médecins Sans Frontieres 2001). The establishment of the Gates Foundation by Bill and Melinda Gates in 2000 gave a big push to PDPs as a new source of available funding. PDPs have also surged in the context of the process of 'vertical dis-integration' in the pharmaceutical industry (Cockburn 2005).

\subsection{PDPs in medical product innovation ecosystems}

PDPs can be understood as functioning in the context of health innovation ecosystems (Papaioannou et al. 2009) that reach beyond national boundaries. The structure of PDPs is shaped, and in turn, can shape the ecosystem in which they operate. Our context for analysis is therefore the broader ecosystem (rather than the industry), which includes the community of organizations (i.e. suppliers and sources of knowledge), institutions (i.e. regulatory authorities and government bodies), and individuals (i.e. managers, policy-makers in disease-endemic countries and patients) that influence PDPs. The ecosystem is composed of multiple players involved in the production and dissemination of drugs, vaccines and diagnostics for neglected diseases, and is influenced by external factors relating to public policy, financing, regulation, intellectual property, human resources and infrastructure, and markets.

The function of the ecosystem can be guided by principles for medical product innovation that responds to health needs. An expert commission under the auspices of the World Health Assembly advanced the following principles (World Health Organization 2006):

- availability: new product development and adequate supply (quantity) of product

- acceptability: usability and appropriateness of the product tailored to specific needs

- quality: product effectiveness, standards for carrying out testing and clinical trials

- affordability: ensuring the financing of product development and procurement, affordable prices

Fig. 1 shows the innovation ecosystem under which PDPs operate and the principles that we consider should guide the development of medical products.

\subsection{PDPs as system integrators}

The characteristics of PDP organizational design that differentiate them from collaborative bilateral or multilateral networks on R\&D for neglected diseases, public institutions and pharmaceutical firms with $R \& D$ capacity include the following:

- They are established as non-profit entities that guarantee them independence and no shareholder expectations of growth and revenue maximization motives. 


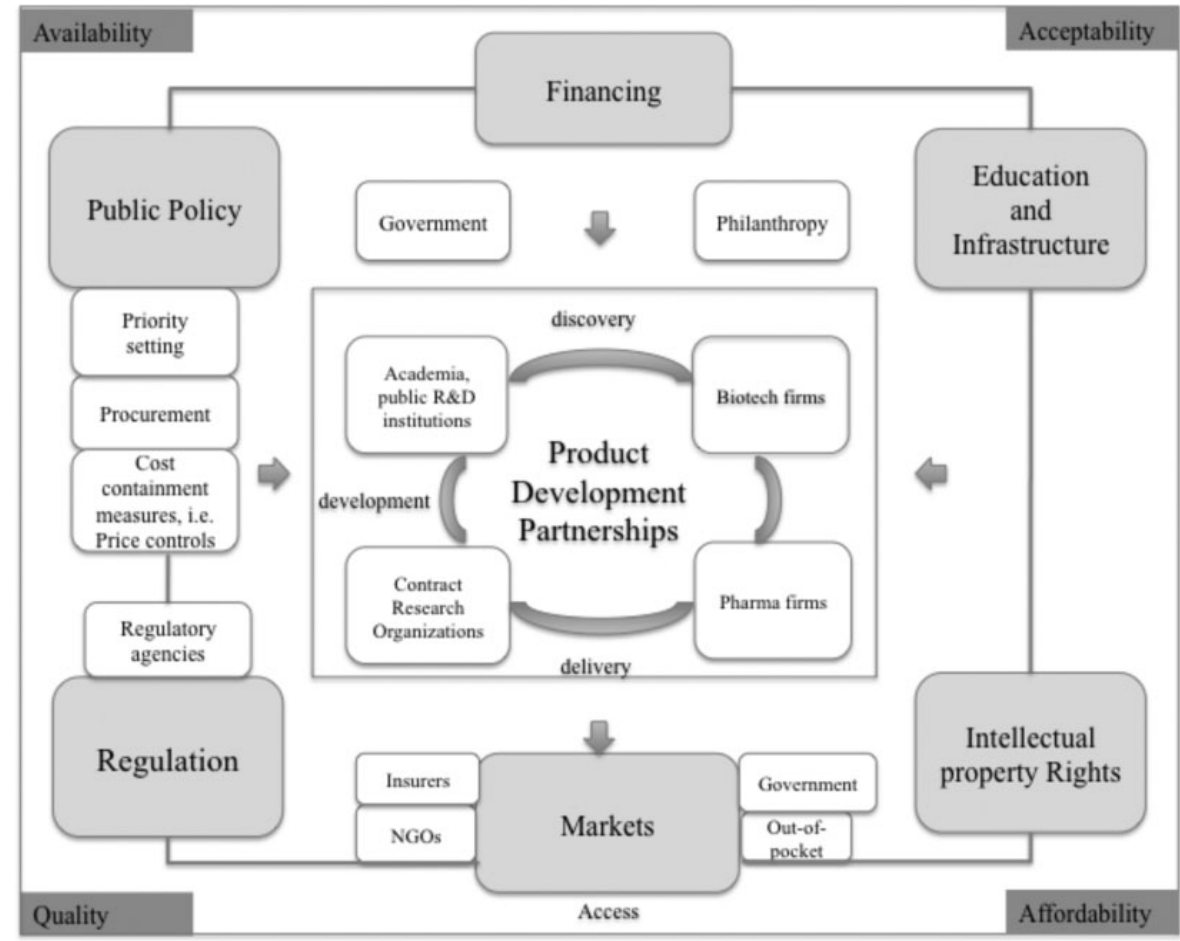

Figure 1. PDPs in medical product innovation ecosystem. Sources: Morel 2005, WHO 2006 (our elaboration).

- Their objective is to develop new medical products that can have a public health impact (specialized, access core to their mission).

- Their focus is on developing 'system integration' capabilities to engage and leverage diverse resources and capabilities of various actors in the R\&D chain.

- They have in-house capabilities to manage a portfolio of R\&D projects.

- External partners often undertake the R\&D activities, though some have in-house R\&D capacity.

PDPs are able to operate on a not-for-profit model, provided that they can receive sufficient funding for their $R \& D$ projects and operations. Thus, a fundamental element of the PDP is to attract funds from donors. Public and philanthropic donors measure returns to investment differently than is the case of shareholders in the pharmaceutical industry R\&D model. As such, philanthropic and public donors do not exert the same pressure as shareholders and venture capitalists do on for-profit firms in terms of maximizing profit. Donors are interested in the end result of PDPs in terms of medical products developed to address unmet health needs.

Funding is also a central enabling factor for R\&D collaboration that takes place through PDPs. It allows PDPs to make propositions attractive to partners and reduces their risk (cost) of engagement. PDP financing is channelled to pay for services (i.e. academia and contract research organizations in clinical trials), and reduces the costs of product development for the industry involved in $\mathrm{R} \& \mathrm{D}$, with clinical trials, manufacturing and registration being the largest cost factors. As described by Chataway et al. (2007), PDPs can play the roles of both integrator and broker among various private and public sector actors. In the innovation ecosystem, PDPs play the role of 'system integrator', which can involve actors at any stage of the R\&D chain, from discovery all the way to implementation and delivery.

For most PDPs, the capabilities/assets for R\&D (e.g. financial resources, vaccine/drug discovery, development, manufacturing and distribution) do not reside with the PDP itself. Accordingly, the main avenue by which PDPs create an R\&D resource base is via collaboration. PDPs search, select and draw in these capabilities/assets from external sources, including academia, pharmaceutical firms, biotechnology firms, contract research organizations, public and philanthropic organizations.

As example of product development through PDPs, Fig. 2 reports the case of the development of a new antimalaria drug. The project was led by Drugs for Neglected Diseases Initiative (DNDi) with the collaboration of TDR.

Traditionally, large pharmaceutical companies are rarely inclined to share knowledge outside the firm, although outsourcing research activities, mergers and acquisitions and in-licensing compounds from biotechnology firms are increasing trends (Schuhmacher et al. 2013). It appears paradoxical that pharmaceutical firms are willing to engage in PDP-led R\&D projects when they are usually locked into searching for the next blockbuster product (Cockburn 2006). According to economic theory, partnerships between large pharmaceutical firms and PDPs in the form of R\&D resource sharing for neglected diseases by 


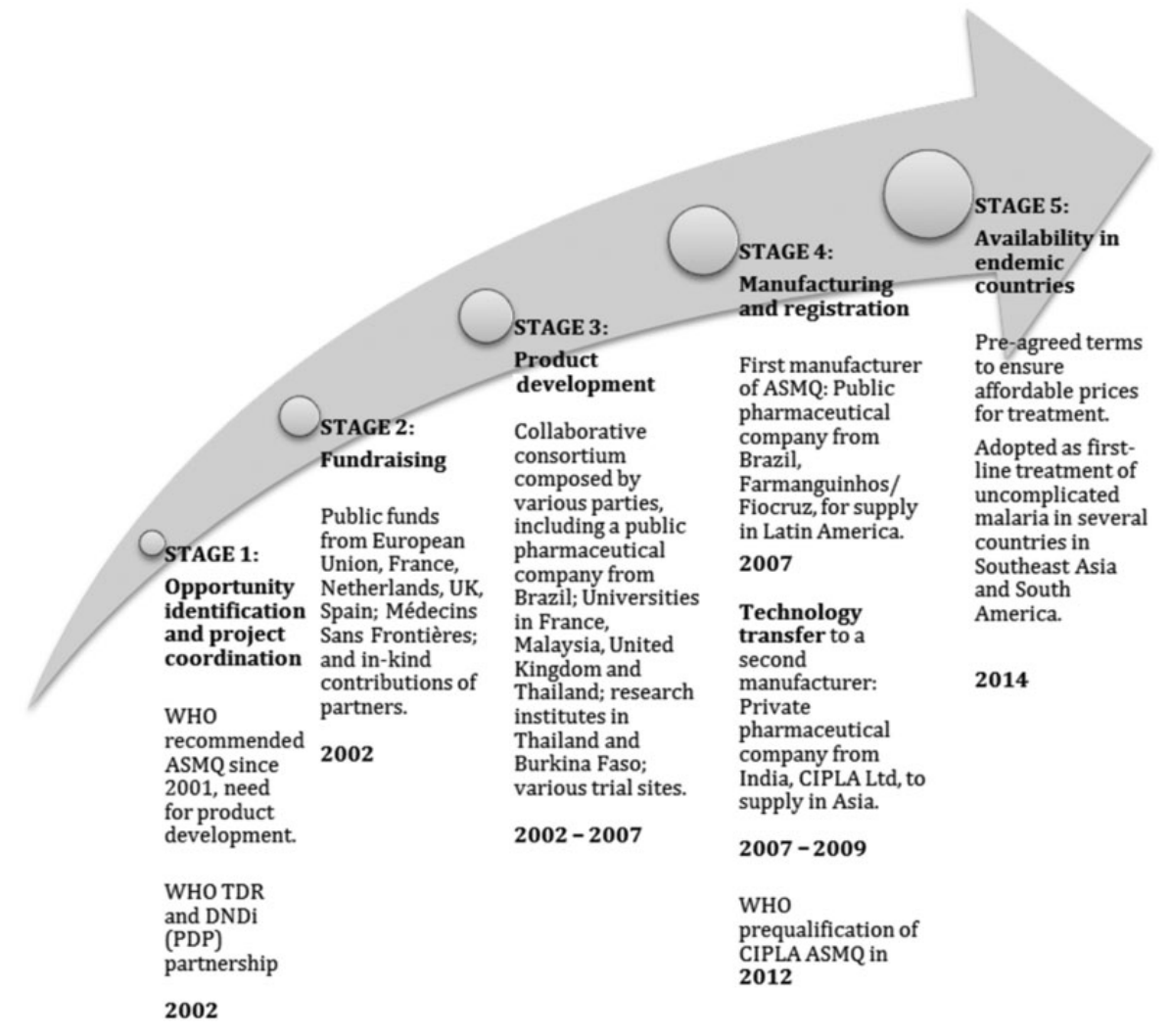

Source: http://ndi.org/treatments/asmq/partnership.html and Wells et al. 2013 (our elaboration).

Figure 2. Example of how PDPs work: development of a fixed-dose combination of existing anti-malaria drugs (artesunate (AS) and mefloquine (MQ)), for Latin America and Southeast Asia.

for-profit companies, constrained by shareholders' values, should not take place. However, through PDPs, such partnerships do, in fact, result. The private sector lacks interest in solely undertaking the range of $\mathrm{R} \& \mathrm{D}$ activities for medical product development on neglected diseases. Yet, within the PDP framework, it appears that the private sector can be induced to collaborate if the costs and risks are reduced and there are other drivers, such as a boost to public relations. By working with PDPs, pharmaceutical firms can still protect shareholder value while sharing access to research tools and technology, and undertaking manufacturing and distributing final products with reduced risks and most costs covered.

For projects in the discovery phase, PDPs tap into the skills in academia, biotechnology and large pharmaceutical firms as knowledge sources, negotiating access for compound libraries, ${ }^{12}$ know-how and compound screening capabilities. PDPs often engage pharmaceutical firms for manufacturing, where the latter provide in-kind contributions, such as infrastructure and personnel time, which aid in low-cost production.

In general, academia and other public research institutions do not have the full range of necessary resources, capabilities or assets to undertake medical product R\&D, even though there is a resolve to address unmet health needs. Public sector institutions involved in $R \& D$ are usually focused on discovery and creating knowledge (upstream) and translational research, while the industry is more focused on product development (downstream) and submissions for regulatory approvals, manufacturing and scaling, distribution and sales. For a PDP, the measure of success is not only product development. As noted in Section 4.2, the aim is to develop new medical products that are effective, high quality, acceptable to the target group, and available at an affordable price. Accordingly, a number of PDPs have agreed to a common definition of 'access' as referring to a coordinated set of activities needed to ensure that the products developed will ultimately have an equitable public health impact (Brooks et al. 2010). Moreover, many PDPs establish 'access' policies. A PDP access policy may include defining upfront the contours of a technology that is appropriate and has affordable resource-limited settings. Generally the target product profile for each R\&D project is developed taking into account the unmet need, the disease profile, and the local environment (including the regulatory framework and purchasing power) in which the product would be delivered. They may also define a product design and set benchmarks for product manufacturing cost and the final price. The PDP product profiling helps clarify expectations for all the partners and subcontractors in $\mathrm{R} \& \mathrm{D}$ projects. 
Most PDPs pick up opportunities for projects based on dormant or discontinued research elsewhere that can be applied to neglected diseases. PDPs producing drugs have generally focused on developing repurposed products rather than NCE (Pedrique et al. 2013). This is also the case in the area of vaccines. For instance, the most clinically advanced malaria vaccine candidate to date (RTS,S) is being developed by the pharmaceutical firm GlaxoSmithKline (GSK), the PDP MVI and PATH. ${ }^{13}$ RTS,S is not a new vaccine candidate. Scientists at GSK, in collaboration with a US Department of Defense biomedical research laboratory, created the vaccine in 1987. The pricing arrangement announced for the RTS,S vaccine for young infants and children in sub-Saharan Africa is that GSK will be paid to cover the costs of the manufacture of the vaccine and will receive a 5\% return (Maleria Vaccines Initiative 2013).

In general, PDPs also aim to keep down the costs of R\&D. While PDPs have to cover the costs of the product development and take into account the costs of product delivery (including registration costs), PDPs are aware that they need to stay as close as possible to the marginal costs of production to meet their access goals. PDPs are able to channel most of their resources to pure $\mathrm{R} \& \mathrm{D}$ activities (in addition to $\mathrm{R} \& \mathrm{D}$ portfolio management and advocacy for funding), as compared to marketing (to promote sales), which may command a larger budget for research in large pharmaceutical firms.

In negotiating the terms of engagement with partners at the development stage, PDPs need to carefully evaluate the access considerations in negotiating the price of manufacturing and distribution by a partner, as well as the acceptability of a partner manufacturing and distributing drugs in disease-endemic countries with longterm sustainability, on a 'at cost' or 'no profit, no loss' basis. PDPs need project managers with good market knowledge and negotiation skills. PDPs can leverage the fact that commercial incentives do exist for certain neglected diseases, such as HIV/AIDS, malaria and TB, which are prevalent in both developed and developing countries. PDPs can also identify target products that may have potential commercial markets in the private sector in disease-endemic countries, where manufacturers can make a margin on sales, and may leverage this incentive in order to obtain better terms (i.e. lower production cost and final sale price) in the public sector within diseaseendemic countries. ${ }^{14}$ PDPs can assist in bringing overall costs down by leading and financing the registration processes, or by finding other partners for this purpose.

\subsection{Governance of PDPs}

PDPs maintain governance independence as self-established entities, though they depend on external financing. The management of $R \& D$ projects involves partners that are vertically disintegrated, and this internal management structure brings flexibility to PDPs in their decisionmaking. There is little pressure for PDPs to expand, as is the case with pharmaceutical firms that often face pressure to undertake mergers and acquisitions in order to keep up with the growth expectations of shareholders. Pressure to contract in size is more likely, in the case of reduced funds.

In the PDP analysis, it makes sense to give attention to the role of R\&D managers and managerial processes (technical advisory body, board and managers), as the PDPs' main job is to build and manage R\&D project portfolios. Managers play the critical role of coordinating and overseeing partners' separate tasks and building synergies, as most R\&D activities undertaken by PDPs are undertaken outside of the PDP. The leadership in terms of decisionmaking remains within PDPs, while in most PDPs, the $R \& D$ activities are outsourced to partners, which have been described as 'virtual' R\&D organizations (Grace 2006, 2010). PDPs build specialized capabilities in project portfolio management by focusing on a single type of medical product and a single disease or a core set of diseases. Such a framework endows PDPs with diseasetype experience that biotechnology or pharmaceutical firms rarely have.

The entrepreneurial aspect of PDPs deserves to be highlighted. PDPs are built by individuals or groups of individuals with an idea (their purpose is to drive $R \& D$ into neglected diseases), who identify opportunities within the ecosystem (new sources of philanthropic financing and growing openness to $\mathrm{R} \& \mathrm{D}$ collaboration in the pharmaceutical sector) and design an organizational form under which it may be possible to assemble the resources/ capabilities needed to carry out $\mathrm{R} \& \mathrm{D}$, taking into account the specificities of the market for new products for neglected diseases. The organizational and managerial processes in PDPs include: selecting targets for R\&D projects and management of the project portfolio, including the various alliances/contractors. Managers, advised by boards and technical bodies have a central role in making operational and strategic decisions to identify complementarities and select and align internal and external assets for developing target products, and then in engaging external partners where necessary to access the necessary assets and capabilities. This 'asset orchestration' (Teece 2012) is a core capability that PDPs need to build and continuously strengthen.

Experienced project managers are core assets of PDPs. Once disease and target product profiles are set by the PDP (taking into account scientific, financing and access considerations), project managers source, negotiate and manage partnerships with public and private-sector participants. They drive discovery projects, select which promising candidates to advance to trials or products to advance through the pipeline or projects to terminate. In managing risk, the considerations for PDPs are similar to those for pharmaceutical firms. The overall measure of success in advancing the R\&D portfolio is the number of 
product approvals that meet the target product profile, with few project terminations. PDPs work on the basis of attrition rates and pre-established milestones and timelines. The effectiveness of a PDP is eval;uated through project portfolio management, based on the initial plan. This is the same overall process as in a pharmaceutical or biotechnology company. In general, PDPs have adopted 'private sector' managerial methods for their work. They are not-for-profit, but nevertheless aim to operate efficiently. Donors/funders also monitor PDP performance and may require measures of cost-effectiveness and public health impact, although donor requirements are not harmonized, nor are the processes or measures harmonized among PDPs.

Generally, PDPs have a small, core team of staff with public health and industry experience, whose work is overseen by a board. PDPs try to compensate for their limited internal capacity in terms of their own staff (limited experience in project management from discovery up to development and delivery) by engaging outside expertise in an advisory manner (similar to the WHO TDR model). External expert advisory bodies provide additional technical and scientific expertise. Boards are influential in the overall strategy and portfolio design of PDPs, but project management tends to be left to the project managers who form the core PDP staff. The technical staff members in PDPs also receive advice from technical advisory committees that are composed of experts in medical product development and related areas. The membership of the board mixes skill and experience from the public and private sectors. The incentives for members of the board are not monetary.

\subsection{PDP capabilities}

We now identify several types of capabilities that PDPs in their 'systems integrator' role need to build and maintain. PDPs need strong organizational capabilities to detect and obtain the necessary resources and capabilities, which may reside in multiple sources. Once these resources and capabilities have been obtained, PDPs bring them together into a single $\mathrm{R} \& \mathrm{D}$ project designed to meet its health needs, as well as to make key decisions throughout the project lifetime, such as whether to terminate a project and product pricing. PDPs also require strategic planning capacity, particularly at the initial stage when building the target product profile and in making strategic decisions thereafter, for instance, on the choice of technology and partners. Staff and governance structure is a key source for building the necessary organizational capabilities. The knowledge capabilities required include: knowledge of the diseases, context and demand, knowledge of medical product $R \& D$ at all stages and requirements for product approval. PDPs also require negotiation, strategy and marketing capabilities in relation to contracting services, building R\&D collaborations, and mobilizing funding and

broader public support for their activities. The financial capability of PDPs is directly related to their ability to detect and mobilize external funding sources. Communication and relational capabilities are also central in the PDP structure, which requires frequent interaction with donors, endemic-country governments and partners, among others. Finally, PDPs require the capacity to adapt to changes in their environment, such as: flux in the burden of diseases, financial resources, government priorities and the entrance or exit of other initiatives on medical product innovation for neglected diseases.

\section{PDPs: Variety within the landscape}

While PDPs share common characteristics, there are important differences among PDPs (see Table 1). PDPs vary in their legal form, scope, internal structure and how they make strategic choices.

Table 1. Common characteristics and differences of PDPs

PDP Common Characteristics

Non-profit institutions

The objective is product development of medicines, diagnostics, vaccines and biologicals for neglected diseases

Priority-setting is driven by medical needs: products developed need to be affordable and adequate to the local context to facilitate uptake. Define the target product profile. Requires low cost of product manufacturing and selling price

The public health goal and R\&D objective of PDPs drive their strategic choices (i.e. priority setting, governance and sources of financing)

Collaborative R\&D model: most PDPs have little or no in-house R\&D activities, work with a diversity of partners from the public and private sectors. Managing the collaborations is the key task of a small core number of in-house staff in PDPs Internal structure: core staff, board, advisory committee

Funding from philanthropic and public sources
PDP Differences

Legal form: stand-alone versus part of another organization, permanent versus temporary

Scope: disease and geographical coverage, type of medical products developed, involvement in implementation phase

Internal structure: size of staff and roles, outsourced versus inhouse R\&D capacity, governance model, external advisory support

Strategic choices: IP policy, partner selection and type of relationship, transfer of technology to developing countries, capacity building for developing countries 


\subsection{Legal form}

While PDPs are all non-profit institutions, they vary in their specific legal form. Most PDPs are stand-alone entities, yet a few are part of a larger organization (i.e. MVP and MVI are part of PATH, the Sabin PDP is part of the Sabin Vaccine Institute). Likewise, most PDPs are registered as non-governmental organizations (i.e. IAVI and TB Alliance), while some are recognized as international organizations (i.e. DNDi, FIND and MMV in Switzerland). PDPs are generally created as a permanent institution, but some PDPs, particularly those that are a project of a larger institution, can be of a temporary nature, to complete a particular goal (i.e. develop a medical product for a specific disease target) and are discontinued thereafter (i.e. MDP ceased activity in 2009, although the founding organizations continue to carry out similar work).

\subsection{Scope}

PDPs vary in scope, including: the terms of their disease coverage, geographical area for which they target their medical products, the type of medical product they develop (medicine, microbiocide, vaccine or diagnostic), and the level of involvement of the PDP in activities during the implementation phase.

Table 2 classifies the PDPs in accordance with the type of medical product they aim to develop. We identified 15 PDPs for vaccines, four PDPs for new medicines, four PDPs for microbiocides, and two PDPs for diagnostics.

The variance in the disease coverage of PDPs is presented in Appendix 1. Most PDPs focus on a single disease, although some PDPs cover up to six diseases. Malaria is the disease most covered. The profile of each disease presents specific challenges for medical product development through the PDP model. For example, while most neglected diseases affect particular geographical regions or countries, some diseases such as HIV/AIDS, malaria and TB have a broader geographical reach in terms of disease burden. In turn, this creates some level of market incentives for private partners (i.e. populations in developed countries travelling to endemic-ridden areas in developing countries for tourism or military missions).

Disease profiles also vary in their mortality rates and incidence. Moreover, the scientific and knowledge challenges vary among diseases (i.e. whether or not any products are currently available for prevention/treatment or cure).

PDPs also vary in their level of involvement in the latestage development process. While all PDPs work from the point of discovery to product development, some PDPs stop at the point where the product is developed, while others continue to follow up implementation activities, including assisting in product pre-qualification by WHO, national registration and uptake and delivery in endemic countries.
Table 2. Type of medical product by PDP

\begin{tabular}{llllll}
\hline & Drug & Vaccine & $\begin{array}{l}\text { Vector } \\
\text { control } \\
\text { products }\end{array}$ & Microbicide & Diagnostic \\
& & & & \\
AERAS & & $\mathrm{X}$ & & \\
MMV & $\mathrm{X}$ & & & \\
DVI & & $\mathrm{X}$ & & \\
EVI & & $\mathrm{X}$ & $\mathrm{X}$ & \\
IVCC & & & $\mathrm{X}$ & \\
IAVI & & $\mathrm{X}$ & & \\
OWH & $\mathrm{X}$ & $\mathrm{X}$ & & & \\
IVI & & $\mathrm{X}$ & & & \\
MVI & & $\mathrm{X}$ & & & \\
MVP & & $\mathrm{X}$ & & & \\
PDVI & & $\mathrm{X}$ & & & \\
Sabin PDP & & $\mathrm{X}$ & & & \\
SAAVI & & $\mathrm{X}$ & & & \\
TBVI & & $\mathrm{X}$ & & & \\
DNDi & $\mathrm{X}$ & & & & \\
CPDD & $\mathrm{X}$ & & & & \\
TB Alliance & $\mathrm{X}$ & & & & \\
IDRI & $\mathrm{X}$ & $\mathrm{X}$ & & $\mathrm{X}$ & \\
CONRAD & & & & $\mathrm{X}$ & \\
HVTN & & $\mathrm{X}$ & & & \\
IPM & & & & & \\
MDP & & & & & \\
FIND & & & & \\
Total & 6 & 14 & 1 & \\
\hline
\end{tabular}

\subsection{Internal structure}

The size of core staff of PDPs varies largely in respect to the size of the PDPs' R\&D portfolio and disease coverage. Some PDPs that have a large portfolio have operations in more than one country or location. We also find some variance in the specific roles of the staff, board and advisory committees and their relationships with each other and partners involved in R\&D projects.

\subsection{Strategic choices}

There is a significant variance in the strategic choices of PDPs in terms of the way $R \& D$ is undertaken, how the portfolio is managed, and in particular, the selection of and agreements with partners. While most PDPs do not carry out R\&D activities in-house, some PDPs do undertake their own research, as in the case of IDRI and AERAS. PDPs also vary significantly in the way they manage their R\&D project portfolios.

As noted in Section 4.3, some PDPs define upfront target product profiles for the R\&D project. However, some PDPs adopt a more flexible approach to determine product profiles, for example, opting to define a pricing strategy for the new medical product at a later stage. PDPs may also vary as to whether they have a defined 'access' policy (guidelines as to how to ensure that the new medical product will be available to those in need). Most PDPs have some basic principles for ensuring access that guide 
negotiations for access to knowledge (compounds for screening), low cost of production from industry partners and royalty-free licenses, at least for endemic countries.

In some PDPs, negotiations and relationships with partners are guided by broader policies, in areas such as intellectual property (IP). An IP policy serves in some PDPs to inform their strategy for the management of intellectual property rights (IPRs), in particular to ensure that IPRs do not create obstacles for the PDP to access know-how and assets, affordability of new products, and follow-on R\&D. However, in some PDPs, decisions on IP management are taken on a case-by-case basis, which is considered to provide the PDP with greater flexibility. Overall, there is significant variance in PDP practices on IP (Muñoz 2014). Some PDPs define at the outset that IP should generally not be sought for any product developed, while others define that the partner can claim or share with the PDP the IP from a potential product along with licensing terms (i.e. non-exclusive or exclusive terms of licenses for pre-existing IP or new products developed). PDPs may also have particular policies concerning the level of control that the PDP, partner or funder may have over the R\&D project (decision-making). PDPs generally face greater pressure from partners to have a stake in decision-making when the financial input of the partner is substantial. PDPs may also have particular policies concerning funding sources (such as specifying a minimum percentage of the PDP budget that should be covered by public as opposed to private funding). PDPs also vary in the extent to which they consider capacity building and the transfer of technology to developing countries to be a part of their mission. For example, DNDi includes these activities as a part of its mandate. In South Africa, SAAVI is linked to the national Medical Research Council, and its work includes programmes to support community involvement and education interventions in relation to HIV issues.

There are numerous projects that include the transfer of technology to developing countries, such as the involvement of the firm Zenufa, based in Tanzania, as a second manufacturer of ASAQ (a DNDi product). Another example is the meningitis vaccine MenAfriVac, manufactured by the Serum Institute of India Ltd, Pune, India (a product from MVP). The decision on whether to go with a manufacturer in a developed country, or with clinical research organization from a developing country is also a strategic one. Considerations include: the cost of production and knowledge of the disease and local context to promote affordability and uptake of the medical product in endemic countries.

\section{Discussion}

So far, we have shown that PDPs contribute to increasing $R \& D$ in order to address the lack of new medical products for neglected diseases. We have also explained how PDPs function within the broader context of medical product innovation ecosystems, and how PDPs are able to bring about R\&D collaboration. We have also identified the core capabilities that PDPs need to build and strengthen in playing the role of 'system integrator' to stimulate $R \& D$ in neglected diseases. Furthermore, we have analysed the variety among the PDP landscape. We now discuss the potential shortcomings of the organizational form and current operation of PDPs.

\subsection{Constraints on the determinants of R\&D productivity}

PDPs still appear to have limited R\&D capabilities. In the case of pharmaceuticals, to date PDPs have focused to a substantial extent on 'low-hanging fruit': existing drugs being evaluated for new indications, new formulations of existing drugs, novel fixed-dose combinations, but not NCE. PDPs have yet to prove whether they can develop NCE, though there are a number of NCE projects in latestage clinical trials. NCE are riskier to invent than finding new uses for existing drugs or new formulations. The latter can be developed in a shorter time frame, and thus can be delivered to those in need of a shorter time frame. Nevertheless, the discovery of new NCE will be needed to achieve substantial improvements in terms of therapeutic benefits over existing drugs. Transaction costs and coordination costs are higher and more complex. Mobilizing sufficient financing for projects on NCE is a major challenge.

Project managers in PDPs need to be highly skilled in order to accomplish the range of activities they may be entrusted with, or if these activities are separated among project managers (by R\&D phase or activity), they will need to be highly coordinated among them (i.e. scientific expertise, evaluating licensing opportunities and designing appropriate clinical trials).

The size of PDPs may vary, though generally they are small organizations. The empirical evidence on the relationship between firm size and innovation is inconsistent (Cohen 2010). Some empirical literature finds that in the pharmaceutical industry, size confers an advantage. Henderson and Cockburn (1996) found that discoveries in larger pharmaceutical firms are more productive, deriving from economies of scope and scale. Yet in drug development, large firms have the advantage of scope, rather than returns to scale (Cockburn and Henderson 2001). However, small firms (such as biotechnology firms) can be highly innovative. The share of NCE attributable to small biotechnology and pharmaceutical firms has increased to nearly 70\% since 1980 (Munos 2009). Moreover, the large scale of $\mathrm{R} \& \mathrm{D}$ portfolios in large pharmaceutical firms and trends in growth via mergers and acquisitions have not led to their increased innovativeness in terms of newly approved NCE. 
PDPs with small project portfolios may have a perverse incentive to cling onto projects that should otherwise be terminated. There is evidence that single-product early-stage firms are more reluctant to abandon the development of their only viable drug candidates, in contrast to firms with multiple products in development (Guedj and Scharfstein 2004).

\subsection{Constraints on financing and priority setting}

Governments of disease-endemic countries, global health organizations (particularly WHO) and, public and philanthropic donors lack coordinated R\&D priority agendas and funding efforts, based on the global burden of diseases. Currently activities are highly disjoined. ${ }^{15}$ This lack of coordination is also reflected among PDPs.

PDPs, as has been pointed out with respect to other multi-stakeholder institutions in global health, derive their legitimacy from their effectiveness in improving specifically defined health outputs and outcomes, in contrast to traditional multilateral agencies, which derive legitimacy from multi-government representation and deliberation (Sridhar 2012). In PDPs, donors decide on the priority areas for funding, the conditions attached to fund disbursements, instruments for control, transparency requirements etc. These requirements are not harmonized among PDPs, nor are they made public. The risk is that the priorities of governments, particularly from endemicdisease countries, do not match those of the donor. Thus the R\&D efforts made by PDPs may deliver products that will not find entry in disease-endemic countries. Currently there is no assurance that the current portfolio of PDPs' $R \& D$ projects will match the expectations of diseaseendemic countries.

PDPs maintain close relationships with partners in collaborative R\&D schemes. The interests and priorities of various partners, public and private, can be at odds. The PDP has the role of neutrally managing these tensions, but it is not exempt from influence. Hence, PDP access and other related policies are critically important. Not all PDPs openly disclose their policies for the establishment of partnerships. None disclose the details of the deals made. While this is standard practice in the pharmaceutical industry, in pursuing the public health objectives of PDPs in the non-profit framework, greater transparency should be expected.

PDPs, as independent entities, could use added oversight from the global public health community. Currently some level of oversight is exerted only privately by funders. WHO could provide additional leadership in establishing priority areas for R\&D in neglected diseases and could coordinate with other new multi-stakeholder institutions that assist in the purchasing and disbursement of new medical products such as the Global Fund to Fight AIDS, Tuberculosis and Malaria and the GAVI Alliance. However, the ability of countries to align their priorities for programmes with the budget at WHO is currently restricted. Member States approve and decide on the use of only the portion of the budget that is financed by Member State contributions (about $25 \%$ of total funding), while donors decide on the use of extra-budgetary (voluntary) funding (over $80 \%$ of total funding) from State and non-State actors. ${ }^{16}$

In addition, donors, especially philanthropic foundations, are not responsive to any broader global health community. Their legitimacy, as in the case of PDPs, rests in the effectiveness of their interventions, but is not linked to any accountability to governments. With the extent of their resources, they are able to exert enormous influence on global health policies. The interviews we conducted point out that PDPs are not always clear in terms of who is setting the priorities for the PDP. Moreover, various interests are aligned, whether it is the funder, (i.e. with the Bill and Melinda Gates Foundation being the largest philanthropic donor), the board, the pharmaceutical industry partner, or the government of endemicdisease countries. When a representative of a PDP was interviewed, we were told:

When Gates says that we should increase efforts for vaccines, we know that the risk for PDPs not in the vaccine field is real.

There could be potential conflicts of interests in the board, for example, when an active pharmaceutical company representative or funder (i.e. Gates Foundation or Médecins Sans Frontiers) is on the board. PDPs do not seem to have a clear strategy on how to tackle the issues. Some PDPs want to maintain independence and give assurance of being a neutral catalyst for $\mathrm{R} \& \mathrm{D}$, while others consider it to be of great importance to have key partners represented on the board.

PDP financing is not assured on a long time horizon. PDPs are highly vulnerable to fluctuations in financing, especially at times of financial downturns which affect governments and donors. Public and donor financing to PDPs are reported to have decreased in the light of the economic downturn since 2008, and are down by US $\$ 128.7$ million (Policy Cures 2012). Furthermore, PDPs must invest considerable resources to be used in fundraising and public relations. They have to undertake marketing and advocacy activities to attract new funding. PDPs' R\&D portfolios are mostly in the early stages (development and early clinical stages), with important exceptions. As projects progress to larger clinical trials, the costs will likely increase significantly, together with total funding needs. There may not be adequate cost estimations of the total funds needed for completion. Some PDPs are already struggling to ensure the estimated funding required for their phase III projects (as is the case with DNDi projections).

Some PDPs have been experimenting with alternative means to raise financing, in addition to advocating for increased resource allocations from the global health 
community. For example, IDRI created three for-profit start-ups (biotechnology companies) as a means to continue financing for its non-profit arm, including licensing vaccine adjuvants to pharmaceutical firms for developed country markets that were originally developed for neglected diseases (Schubert 2009). One problem identified is that PDPs cannot attract venture capital or some types of grants (i.e. small business grants in the USA) that are available to small innovative firms, but not to non-profits. However, the relationship between the non-profit and for-profit arms of PDPs is likely to increase tensions with respect to the public interest mission of PDPs.

\subsection{Constraints of access and delivery}

The PDP setup creates tensions between incentives for R\&D and access goals. In practice, managing an agenda of R\&D plus access is complex. A case example is defining the product price and IPR policy. In cases where the market is too small to stimulate competition, products will need to be supplied at cost, or at a price corresponding to a small margin above the lowest manufacturing costs to ensure sustainability of production. Yet, due to asymmetric information, PDPs can be paying higher than 'at cost' to partners, who may also seek IPR protection for the new medical products, in particular, for diseases that have some commercial market (i.e. HIV/AIDS, malaria, TB and meningitis).

PDPs also face the challenges of ensuring that the end users can access products once they are developed. Introducing new tools for various indications has often been associated with a significant delay between global availability and local adoption. Donors are funding product development, but not product delivery. The capacity to conduct research to support and sustain public health initiatives in developing countries remains weak, which is a barrier to the long-term availability of existing products.

\subsection{Constraints of contracting and coordination problems}

The disintegrated R\&D structure of the majority of PDPs raises contracting problems and transaction costs, as compared to centralized, vertically integrated $R \& D$ within a single organization (Cockburn 2005).

Problems of asymmetric information exist in contracting with partners. Academic researchers may be better aware of the true value of their research, and may consult contract research organizations about the costs of clinical trials, and pharmaceutical firms about the cost of manufacturing and distribution. Moral hazard may occur, in particular in manufacturing. Given that the PDPs cover most of the costs, the firm involved is therefore more likely to take risks. The contractual terms of PDP collaborations are not disclosed. Non-disclosure of contractual terms makes it more difficult for PDPs to share information, learn from each other's experience and share it with outside R\&D projects. In particular, IPR terms can limit the freedom of PDPs to coordinate $R \& D$, grant sublicenses for manufacturing and other activities with third parties.

We observe that PDPs tend to select those with whom they have previously worked. A possible explanation is incomplete information on potential partners. In doing so, opportunities for collaboration may be missed, for example, with partners from disease-endemic countries.

PDPs operate independently, with no overall coordinating entity or public policy guidance on priority setting, other than their own PDP governance structure and the pursuit of their mission. The only coordinating entity, to some extent, is the Gates Foundation. As a funder of several PDPs, the Foundation sees the broader picture of PDPs' R\&D projects: yet, an analysis of PDP portfolios or other initiatives to coordinate at a broader level are not disclosed to the public. PDPs may be subject to the problems that pharmaceutical firms face in pursuing the same leads to dead ends, making unnecessary efforts to replicate screening, and studies that others have already undertaken.

There can also be a lack of coordination and collaboration among PDPs, leading to unnecessary duplication of efforts, though we do not have sufficient evidence to explore the extent to which this may be affecting $R \& D$ outcomes. The topic of competition in a non-profit economy is not often explored. In the case of PDPs, it is evident that PDPs may be competing with one another for the same select sources of funding to capture resources. The overlapping of R\&D portfolios in terms of diseases or leads may not constitute a problem in itself, given the high levels of failure that can be expected in medical product development, particularly vaccines and new drugs. However, resources may be wasted, and spillovers may be foregone by a potential lack of cooperation and sharing of information and resources among PDPs. If the sources of financing for PDPs are not assured, or if policies are not implemented by governments and funders to regulate PDP behaviour in another direction, this competitive environment can be expected to continue. However, there are indications that PDPs are working to increase coordination and collaboration among themselves. For example, the TB Alliance granted DNDi a royalty-free license to develop anti-TB compounds for use against other neglected diseases in the R\&D portfolio of DNDi.

Sharing information among PDPs can also serve to build collective bargaining power to achieve better deals and to strengthen their future negotiating positions with partners, particularly with pharmaceutical firms. PDPs could share with one another their experiences in negotiating with partners, the terms of deals, including a 
better understanding of how firms define terms such as: 'at cost', 'no loss', 'fully burdened manufacturing cost' and 'cost plus', which may significantly vary the cost of a PDP R\&D project, and strategies for IPR management. PDPs could also work more closely in their common operations, in areas such as advocacy to donors and technology platforms to bring down costs and increase effectiveness.

\subsection{Constraints of insufficient transparency}

As independent non-profit organizations, PDPs face demands for accountability from various sources, including: donors, endemic-country governments, partners and end users of the medical products that they aim to treat. They are legally accountable in terms of compliance with the health regulatory standards for new medical products in general. However, PDPs could improve their transparency and disclosure, as well as performance assessment mechanisms. PDPs and their partners neither systemically nor publicly disclose all relevant scientific and clinical data that could be useful, for example, in cases when clinical trials fail to avoid making the same mistakes or following the same leads. PDPs need to make the terms of their deals with partners, financial allocations and costs of their $R \& D$ projects more transparent in order to allow proper evaluation. PDPs could increase their credibility and legitimacy by establishing governance instruments and institutional policies to reduce the risk of capture or undue influence by donors and other actors and could avoid conflicts of interests in managing their R\&D portfolios. Some PDPs have established policies, for example, with respect to ensuring multiple sources of financing to avoid donor capture, and policies on access and management of IPR, but these are isolated initiatives. There is also a lack of systemic assessment of PDPs, based on a commonly agreed upon methodology or metrics. Despite the growing amount of resources being challenged for neglected disease R\&D to PDPs, there are no reliable methods or regular assessment reviews of PDP performance, as compared to other alternatives (Ridley 2004).

\subsection{Constraints of insufficient use of capabilities in disease-endemic countries}

Not all PDPs see their mission as seeking to build up the capacity of developing countries themselves and technology transfer to undertake R\&D on treatments for those diseases that particularly affect disease-endemic countries. Greater R\&D capacity in developing countries has many benefits, such as lower R\&D costs, price of manufacturing and distribution, and increasing market competition to drive down long-term prices for medical products. In the case of the meningitis vaccine developed by the PATH
MVP, the India Serum Vaccine Institute was able to offer to manufacture the vaccine at the target price set by MVI, which would allow endemic-country governments to procure the vaccine at US\$0.50 a dose. No other large vaccine manufacturer was willing to produce at this price. PDPs should seek greater collaboration with emerging economies that are increasing their role in the neglected disease landscape. ${ }^{17}$

\section{Conclusions}

We have described an interesting phenomenon under the lens of the economics of innovation. PDPs are a new form of pharmaceutical R\&D in the area of neglected diseases. We have found evidence that PDPs are able to bring about new medical products. We did not consider the efficiency of the PDP organizational form, as compared to others. Reasons for having not carried out any efficiency analysis are various. In particular, the data needed to undertake such an analysis were not available, and even if the data had been obtained, the absence of counterfactual cases would have strongly limited the scope of the analysis. Moreover, the various PDPs investigated in this paper are not readily comparable because they deal with different diseases and medical products. Thus, the scientific and technological problems they try to solve are of different levels of complexity.

In this study, we exclusively analysed the experience of PDPs in the area of neglected diseases. Nonetheless, there is increasing academic and policy interest in exploring the potential of PDPs in other areas, such as antibiotics. ${ }^{18}$ There is also growing interest in promoting greater collaboration and information sharing to advance drug development, particularly in the pre-competitive stage of discovery. ${ }^{19}$

We find that PDPs act as 'system integrators' that leverage the resources and capabilities of a diverse network of public, philanthropic and private-sector partnerships. PDPs are able to mobilize private firms to join $R \& D$ projects and provide in-kind contributions. By binding together and coordinating the activities of various firms and other organizations, the PDP integrator role is beneficial to all involved. PDPs facilitate access to the financing and exchange of knowledge. Additionally, they diffuse knowledge among the groups that in turn, may also be internalized by individual participants. Public policy should encourage PDP types of activities and $R \& D$ collaborations.

Some of the constraints we found associated with PDPs are: coordination problems, insufficient transparency in contractual terms with partners and the mismatch between the financing horizons of donors and the time frame of medical product development.

The future of the PDP landscape remains uncertain. Some PDPs that have completed their activities (or 
whose funding has ceased) have disappeared, while others have merged into larger PDP organizations. This may be an indication that there is a need for scale and scope in PDP operations, in the context of uncertain financing. It would be useful for PDPs to increase their transparency in their internal operations, their policies on critical issues such as access and IPRs, as well as in their dealings with funders and partners. Such transparency may be forthcoming if greater oversight is undertaken by international health organizations, for instance, the WHO, neglected disease-endemic countries and public funders. An agreement for increased global coordination of priority setting for R\&D and resource allocation directed at neglected diseases, for instance, through the WHO, would serve to direct the work of PDPs in a more coherent and transparent manner. According to Weder and Grubel (1993), private agents have found many ways to internalize R\&D externalities and solve coordination problems that arise from the public good nature of knowledge and research. They call these solutions 'Coasean institutions', according to the principle developed by Ronald Coase (1960), and advance that knowledge externalities induce the creation of private institutions capable of internalizing them. The institution analysed and documented in this paper (the PDPs) clearly represent a new Coasean solution to this broad class of problems, including R\&D and knowledge externalities, as well as coordination failures in decentralized markets for knowledge and new products. $^{20}$

A limitation of this paper is the lack of information available concerning the contractual terms of PDP collaborations with partners and processes for determining how funds are allocated to partners. This information is not publicly available, and it was not possible to collect comparable data. If such information were available, future research could evaluate the performance of PDPs, including resource allocation, selection and termination of R\&D projects and the appropriateness, affordability and health impact of new medical products produced by PDPs, as compared to other sources, or alternatives to promote R\&D in neglected diseases.

\section{Funding}

This work was supported by the Swiss Network of International Studies (SNIS), in partnership with the South Centre and the Drugs for Neglected Diseases Initiative. The paper reflects only the views of the authors.

\section{Acknowledgements}

The authors would like to offer special thanks to Pascale Boulet, and extend thanks to Jean-François Alessandrini, Jean-Pierre Paccaud, Carlos Correa and Germán
Velásquez. Assistance provided by Kevon Swan and Alexandra Bhattacharya was greatly appreciated.

\section{Notes}

1. The diseases concerned are: Buruli ulcer; Chagas disease; cysticercosis; dengue; dracunculiasis; echinococcosis; endemic treponematoses; foodborne trematode infections; human African trypanosomiasis; leishmaniasis; leprosy; lymphatic filariasis;, onchocerciasis; rabies; schistosomiasis; soil-transmitted helminthiases; and trachoma.

2. The inclusion of these diseases is consistent with other studies (Trouiller et al. 2002; Policy Cures 2012).

3. There can be ample variance, depending on the disease (the extent of R\&D gaps, market attractiveness) and the type of product and means of undertaking clinical trials.

4. An AMC programme has yet to be tried for incentivizing new medical products. The first experience in the design of a large-scale pull instrument was the AMC GAVI Alliance initiative, which has been in place since 2009 to make available existing pneumococcal vaccines. It was designed by a group of economists (Levine et al. 2005). Governments and the Gates Foundation made a binding commitment of US\$1.5 billion to fund the pilot AMC for which vaccine manufacturers could bid. In 2010, GSK and Pfizer committed to supply 30 million doses of their pneumococcal vaccines for ten years. These vaccines had recently been approved in Europe and the USA (Synflorix and Prevenar-13) at a maximum price of US $\$ 3.50$ a dose. The two vaccines were selling for an average of $€ 40$ in Europe and US\$90 per injection in the USA. Each manufacturer's share of the AMC funds is disbursed as a subsidy per dose, in addition to the tail price of US\$3.50 thus, the total price goes up to US\$7 for approximately the first $20 \%$ of vaccine doses procured from each manufacturer (Cernuschi et al. 2011). The aim is to enable firms to quickly recover incremental investment costs incurred to allow the scaling up of supply capacity to serve GAVI-eligible countries faster through the WHO and UNICEF as procurement agents. The expectation is that the vaccines will be distributed to 40 developing countries that will pay 15 cents of the US\$3.50, with the remaining cost covered by the AMC. The estimate cost per child receiving the vaccine is US\$4.722 (Scudellari 2011). Some concerns that have been raised include: the costs of the system, transparency by firms on vaccine manufacturing costs and profit margins, geographical scope, eligible purchasing agents, and entry of developing country producers that can lower the vaccine costs (Médecins Sans Frontières 2013). 
5. Some of these proposals include: the Product Development Partnership Financing Facility, the industry R\&D Facilitation Fund the Fund for Research in Neglected Diseases, and a fund within a global framework on health R\&D. These proposals are reviewed in the WHO report (World Health Organization 2012b: 176-9).

6. Our complete list of PDPs includes (in alphabetical order): AERAS; Contraceptive Research and Development (CONRAD); Consortium for Parasitic Drug Development (CPDD); Dengue Vaccine Initiative (DVI); Drugs for Neglected Diseases (DNDi); the European Vaccine Initiative (EVI); Foundation for Innovative New Diagnostics (FIND); Global Alliance for TB Drug Development (TB Alliance); HIV Vaccines Trials Network (HVTN); Infectious Disease Research Institute (IDRI); Innovative Vector Control Consortium (IVCC); International AIDS Vaccine Initiative (IAVI); International Partnership for Microbiocides (IPM); International Vaccine Institute (IVI); Malaria Vaccine Initiative (MVI); Medicine for Malaria Venture (MMV); Meningitis Vaccine Project (MVP); Microbiocides Development Programme (MDP); One World Health (OWH); Paediatric Dengue Vaccines Initiative (PDVI); Sabin PDP; South African AIDS Vaccine Initiative (SAAVI); and the Turberculosis Vaccine Initiative (TVI). To date, we have interviewed several representatives from four PDPs, two of which produce drugs (DNDi and MMV), one of which produces vaccines (MVP) and one of which produces diagnostics (FIND).

7. We include PDPs that are part of a larger PDP organization, (i.e. MVP and MVI are part of PATH; the, Sabin PDP is part of the Sabin Vaccine Institute).

8. Instruments such as direct grants to small and medium firms and for clinical trials in developing countries, milestone or end prizes, purchase or procurement agreements, among others, can be complementary to the role of PDPs, and PDPs themselves can use them.

9. The WHO is the leading directing and coordinating authority for health within the United Nations system. The WHO TDR programme, in existence since 1975, is cosponsored by UNICEF, UNDP and the World Bank. The aim of the programme was to intensify research on major tropical parasitic diseases (taking into consideration that such activities should be carried out mainly in endemic countries), define the research priorities, extend cooperation with national institutions and other governmental and non-governmental organizations in regard to the coordination of research in this field, and mobilize extra-budgetary resources for scaling up these objectives (World Health Assembly 27.52). The TDR was set up mainly as a partnership between public donors, co-sponsors and endemic-country governments represented in an independent board-type structure (UNICEF et al. 2007).

10. MMV was created in 1999. The TB Alliance was established in 2000. In 2003, the DNDi was created as a joint initiative of MSF, TDR and representatives of disease-endemic countries. FIND was also established in 2003.

11. The IDRI was created as a non-profit research institute in 1993.

12. Access to the chemical compound collections of pharmaceutical firms is very important. However, the firms themselves caution that the existing chemical diversity in pharmaceutical firms in search of new drugs is limited (Payne et al. 2007). The portfolio of several PDPs includes projects for radical innovations (i.e. the discovery of NCE).

13. The results of phase III trials of the vaccine's capacity have shown approximately a $50 \%$ success rate.

14. A case example is the combination drug ASAQ developed by DNDi in partnership with Sanofi. It is now registered in over 30 sub-Saharan countries and India, and is prequalified by WHO. DNDi developed ASAQ in collaboration with Sanofi and other partners. It claimed a patent and then licensed it out to Sanofi for African and other developing countries. Under the DNDi/Sanofi agreement, Sanofi has committed to supply the public sector in endemic countries at a no-profit-no-loss maximum price of US\$1. In the private sector, Sanofi is free to sell at market price and pays a royalty back to DNDi, which is reinvested in additional studies. DNDi and Sanofi agreed not to file any new patents: as a result, the drug can be freely produced and distributed by any other pharmaceutical company in the world. DNDi is currently facilitating technology transfer to ensure the production of ASAQ by an African manufacturer.

15. A WHO expert working group (CEWG) proposed a binding $R \& D$ treaty to improve priority setting based on public health needs, and to promote increased government financing for $\mathrm{R} \& \mathrm{D}$ and coordination among public and private R\&D (World Health Organization 2012b). There are proposals by governments, civil societies, and PDPs for the establishment of a global R\&D framework that monitors, coordinates, and finances medical innovations for neglected populations, in the form of a new R\&D treaty (Drugs for Neglected Diseases Initiative and Médecins Sans Frontières 2012) to establish a Global Health R\&D Observatory within WHO.

16. See the WHO document A66/48, WHO Reform, Financing of WHO, 66th World Health Assembly, Provisional Agenda Item 11, 13 May 2013.

17. See So and Ruiz-Esparza (2012).

18. See World Health Organization (2012a).

19. See Ekins et al. (2013). In the case of neglected diseases, openness is facilitated by the particularity 
that funding comes from public sources, and potential profits are nil or low. For other diseases, IP and profit margins are central components of the business strategy of firms, and may be the case for academia, as well. In this context, the incentive for openness and knowledge sharing in product development is weaker, although on the whole, it would be beneficial to speed up medical product development.

20. However, as Weder and Grubel (1993) cautioned, policy has to limit the natural rent-seeking activities of private agents by establishing constraints on the cooperative agreements that take place with firms within the collaborative R\&D structure. In the case where public moneys are being channelled to PDPs, policy can play a role in defining the conditions for disbursement, such that all partners work to fulfil the PDP mission and avoid potential rent-seeking, and promote greater transparency.

\section{References}

Årdal, C. and Røttingen, J. A. (2012) 'Open source drug discovery in practice: A case study', PLoS Neglected Tropical Diseases, 6/9: e1827.

Bio Ventures for Global Health. (2012) Developing New Drugs and Vaccines for Neglected Diseases of the Poor: The Product Developer Landscape. San Francisco, CA: Bio Ventures for Global Health.

Boston Consulting Group. (2010) Path Vaccine Product Development Assessment: Summary of Findings, <http://www.path.org/files/ OTP-bcg-vacc-dev-eval.pdf > accessed 5 August 2014.

Brooks, A. D., Wells, W. A., McLean, T. D., Khanna, W. A. et al. (2010) 'Ensuring that developing countries have access to new healthcare products: The role of product development partnerships', Innovation Strategy Today, 3: $1-5$.

Cernuschi, T., Furrer, E., Schwalbe, N., Jones, A. et al. (2011) 'Advance market commitment for pneumococcal vaccines: Putting theory into practice', Bulletin of the World Health Organization, 89: 913-8.

Chataway, J., Brusoni, S., Cacciatori, E., Hanin, R. et al. (2007) 'The International AIDS Vaccine Initiative (IAVI) in a changing landscape of vaccine development: A public-private partnership as knowledge broker and integrator', European Journal of Development Research, 19: 100-17.

—, Hanlin, R., Mugwagwa, J. and Muraguri, J. (2010) 'Global health social technologies: Reflections on evolving theories and landscapes', Research Policy, 39: 1277-88.

Coase, R. (1960) 'The problem of social cost,', Journal of Law and Economics, 3: 1-44.

Cockburn, I. (2005), 'Blurred boundaries: Tensions between open scientific resources and commercial exploitation of knowledge in biomedical research'. Paper prepared for the Advancing Knowledge and the Knowledge Economy Conference, held 10-11 January 2005, National Academy of Sciences, Washington, DC.

- (2006) 'Is the pharmaceutical industry in a productivity crisis?' In: Lerner, J. and Stern, S. (eds) Innovation Policy and the Economy, Vol. 7, pp. 1-32. Cambridge, MA: MIT Press. and Henderson, R. (2001) 'Scale and scope in drug development: Unpacking the advantages of size in pharmaceutical research', Journal of Health Economics, 20: 1033-57.

Cohen, W. (2010) 'Fifty years of empirical studies of innovative activity and performance'. In: Hall, B.H. and Rosenberg, H. (eds) Handbook of the Economics of Innovation, Vol. 1, pp. 129-98. Elsevier B.V.

DiMasi, J., Hansen, R. and Grabowski, H. (2003) 'The price of innovation: New estimates of drug development costs', Journal of Health Economics, 22: 151-85.

Drugs for Neglected Diseases Initiative and Médecins Sans Frontières. (2012) Medical Innovation for Neglected Patients, $<$ http://www.msfaccess.org/sites/default/files/MSF_assets/ Innovation/Docs/MedInno_Report_MedInnforNegPatients_ ENG_2012.pdf $>$ accessed 24 June 2013 .

Ekins, S., Waller, C., Bradley, M., Clark, A. and Williams, A. (2013) 'Four disruptive strategies for removing drug discovery bottlenecks', Drug Discovery Today, 18: 265-71.

Grace, C. (2006) Developing New Technologies to Address Neglected Diseases: The Role of Product Development Partnerships and Advanced Market Commitments. London: DFID Health Resource Centre.

- (2010) Product Development Partnerships (PDPs): Lessons from PDPs Established to Develop New Health T echnologies for Neglected Diseases. London: DFID Human Development Resource Centre.

Guedj, I. and Scharfstein, D. (2004) 'Organizational scope and investment: Evidence from the drug development strategies and performance of biopharmaceutical firms', NBER Working Papers, 10933. Cambridge, MA: National Bureau of Economic Research.

Hegde, D. and Sampat, B. N. (2014) 'Can private money buy public science? Disease group lobbying and federal funding for biomedical research', Forthcoming in Management Science. Available at SSRN: <http://ssrn. com/abstract $=1962937>$ accessed 24 June 2013 .

Henderson, R. and Cockburn, I. (1996) 'Scale, scope, and spillovers: The determinants of research productivity in drug discovery', RAND Journal of Economics, 27: 32-59.

Hobday, M., Davies, A. and Prencipe, A. (2005) 'Systems integration: A core capability of the modern corporation', Industrial and Corporate Change, 14: 1109-43.

International Federation of Pharmaceutical Manufacturers and Associations (2012) Status Report on Pharmaceutical R\&D to Address Diseases that Disproportionately Affect People in Low and Middle Income Developing Countries <http://www.ifpma. org/fileadmin/content/Publication/2013/IFPMA_R_D_Status Report_Neglected_Conditions.pdf $>$ accessed 24 June 2013.

Juliano, R. L. (2013) 'Pharmaceutical innovation and public policy: The case for a new strategy for drug discovery and development', Science and Public Policy, 40: 393-405.

Kremer, M. (2001) 'Creating markets for new vaccines-Part I: Rationale'. In: Jaffe, A., Lerner, J. and Stern, S. (eds) Innovation Policy and the Economy, pp. 35-72. Cambridge, MA: MIT Press.

Levine, R., Kremer, M. and Albright, A. (2005) Making Markets for Vaccines: Ideas to Action. Report of the Center for Global Development Advance Market Commitment Working Group. Washington, DC: Center for Global Development.

Light, D. and Lexchin, J. (2012) 'Pharmaceutical research and development: What do we get for all that money?', BMJ, 345: e4348.

— and Warburton, R. (2011) 'Demythologizing the high costs of pharmaceutical research', BioSocieties, 6: 34-50. 
Moran, M. (2005a) 'A breakthrough in R\&D for neglected diseases: New ways to get the drugs we need', PLoS Medicine, 2/9: e302.

- (2005b) The New Landscape of Neglected Disease Drug Development. London: LSE and Wellcome Trust.

- Guzman, J., Ropars, A. L. and Illmer, A. (2010) 'The role of product development partnership in research and development for neglected diseases', International Health, 2: 114-22.

Médecins Sans Frontières. (2001) Fatal Imbalance: The Crisis in Research and Development for Drugs for Neglected Diseases, $<$ http://www.doctorswithoutborders.org/publications/reports/ 2001/fatal_imbalance_short.pdf > accessed 24 October 2012.

(2013) Global Vaccines Community Must Bring Price of New Vaccines Down, <http://www.msfaccess.org/our-work/ vaccines/article/2040> accessed 5 August 2014.

Medicines Malaria Venture. (2012) Fact Sheet: The RTS,S Malaria Vaccine Candidate, <http://malariavaccine.org/ files/UpdatedRTSS_FactSheet_21April2010.pdf $>$ accessed 4 August 2014.

Morel, C., Acharya, T., Broun, D., Dangi, A. et al. (2005) 'Health innovation networks to help developing countries address neglected diseases', Science, 309/5733: 401-4.

Morgan, S., Grootendorst, P., Lexchin, J., Cunningham, C. and Greyson, D. (2011) 'The cost of drug development: A systematic review', Health Policy, 100: 4-17.

Munos, B. (2009) 'Lessons from 60 years of drug discovery', Nature Reviews Drug Discovery, 8: 959-68.

Muñoz, V. (2014), 'Intellectual property management in nonprofit medical product development partnerships' (unpublished manuscript).

Nelson, R. B. (1959) 'The simple economics of basic scientific research', The Journal of Political Economy, 67/3, pp 297-306.

Papaioannou, T., Wield, D. and Chataway, J. (2009) 'Knowledge ecologies and ecosystems? An empirically grounded reflection on recent developments in innovation systems theory', Environment and Planning C: Government and Policy, 27: 319-39.

Payne, D., Gwynn, M., Holmes, D. and Pompliano, D. (2007) 'Drugs for bad bugs: Confronting the challenges of antibacterial discovery', Nature Reviews Drug Discovery, 6: 29-40.

Pedrique, B., Strub-Wourgaft, N., Some, C., Olliaro, P. et al. (2013) 'The drug and vaccine landscape for neglected diseases (2000-11): A systematic assessment', The Lancet Global Health, 1/6: e371-9, <http://www.thelancet.com/journals/ langlo/article/PIIS2214-109X(13)70078-0/abstract > accessed 28 October 2013.

Policy Cures. (2012) G-FINDER: Global Funding of Innovation for Neglected Diseases, Report for 2012. Sydney, NSW: Australia: Policy Cures.

Ridley, R. (2001) 'Putting the partnership into public-private partnerships', Bulletin of the World Health Organization, 79: 694-7.

- (2004), 'Product development public private partnerships for diseases of poverty: Are there more efficient alternatives? Are there limitations?'. Paper presented at Initiative on Public-Private Partnership for Health Meeting, held 15-6 April 2004, London.
Røttingen, J. A., Regmi, S., Eide, M., Young, A. et al. (2013) 'Mapping of available health research and development data: What's there, what's missing, and what role is there for a global observatory?', The Lancet, 382/9900: 1286-307.

Schubert, C. (2009) 'Steve Reed', Nature Biotechnology, 27/11: 971-2.

Schuhmacher, A., Germann, P., Trill, H. and Gassmann, O. (2013) 'Models for open innovation in the pharmaceutical industry', Drug Discovery Today, 18: 23-4.

Scudellari, M. (2011) 'Are advance market commitments for drugs a real advance?', Nature Medicine, 17: 139.

So, A. and Ruiz-Esparza, Q. (2012) 'Technology innovation for infectious diseases in the developing world', Infectious Diseases of Poverty, 1/2: 1-9.

Sridhar, D. (2012) 'Who sets the global health research agenda? The challenge of multi-bifinancing', PLoS Med, 9/9: e1001312.

Teece, D. (2012) 'Dynamic capabilities: Routines versus entrepreneurial action', Journal of Management Studies, 49: 1395-401.

Trouiller, P., Olliaro, P., Torreele, E., Orbinski, J. et al. (2002) 'Drug development for neglected diseases: A deficient market and a public health policy failure', The Lancet, 359: 2188-94.

Toole, A. (2012) 'The impact of public basic research on industrial innovation: Evidence from the pharmaceutical industry', Research Policy, 41: 1-12.

UNICEF/UNDP/World Bank/WHO Special Programme for Research and Training in Tropical Diseases. (2007) Making a Difference: 30 Years of Research and Capacity Building in Tropical Diseases. Geneva: World Health Organization.

Webber, D. and Kremer, M. (2001) 'Perspectives on stimulating industrial research and development for neglected infectious diseases', Bulletin of the World Health Organization, 79: 735-41.

Weder, R. and Grubel, H. (1993) 'The new growth theory and coasean economics: Institutions to capture externalities', Review of World Economics (Weltwirtschaftliches Archiv), Springer, 129/3: 488-513.

Wells, S., Diap, G. and Kiechel, J. (2013) 'The story of artesunate-mefloquine (ASMQ), innovative partnerships in drug development: Case study', Malaria Journal, 12: 68.

World Health Organization. (2006) Public Health-Innovation and Intellectual Property Rights: Report of the Commission on Intellectual Property Rights, Innovation and Public Health. Geneva: World Health Organization.

(2010) First WHO Report on Neglected Tropical Diseases: Working to Overcome the Global Impact of Neglected Tropical Diseases. Geneva: World Health Organization.

- (2012a) The Evolving Threat of Microbial Resistance, Options for Action. Geneva: World Health Organization.

(2012b) Research and Development to Meet Health Needs in Developing Countries: Strengthening Global Financing and Coordination. Report of the Consultative Expert Working Group on Research and Development: Finance and Coordination, $<$ http://www.who.int/phi/CEWG_Report_5_April_2012.pdf> accessed 5 August 2014. 


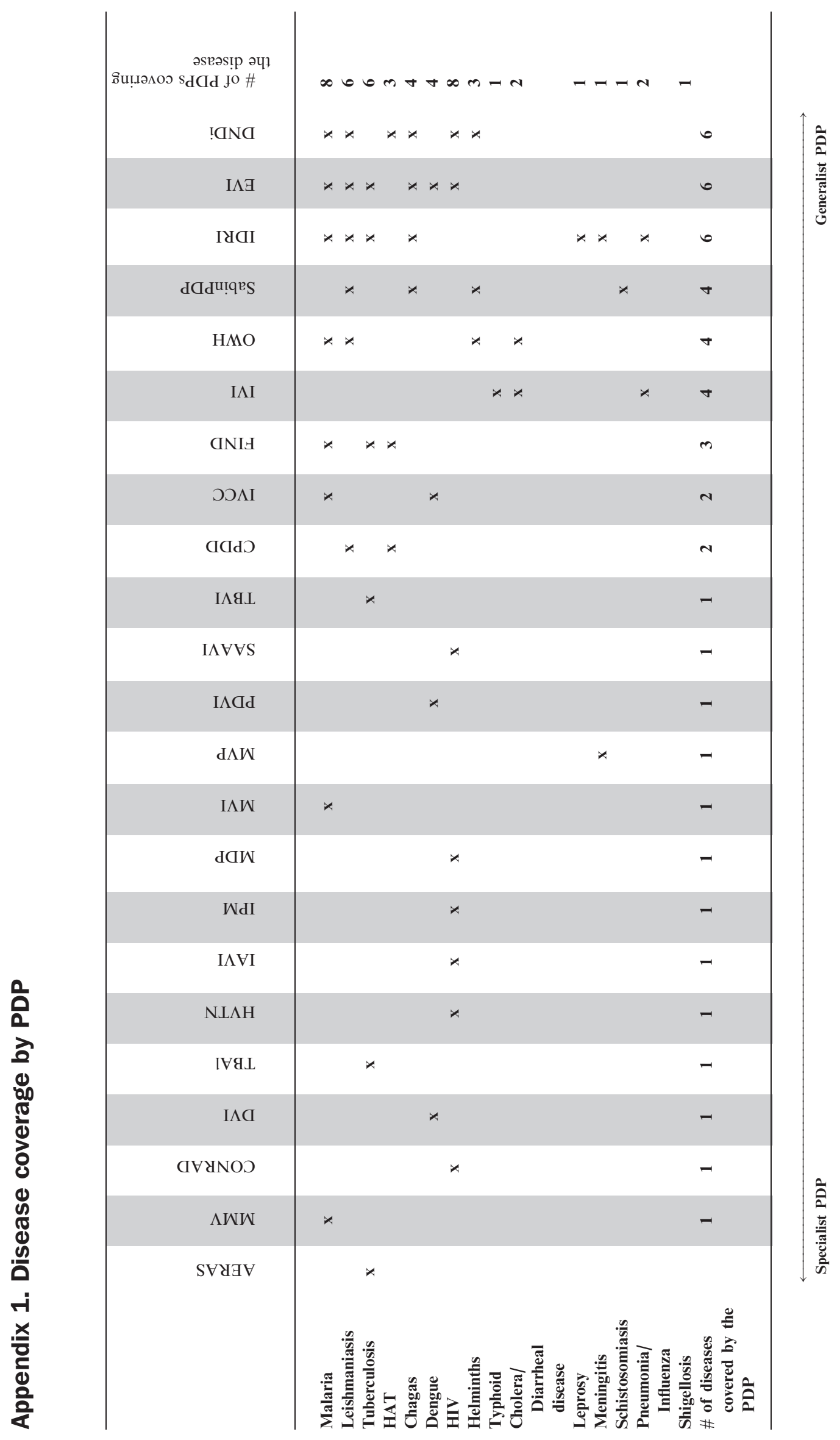




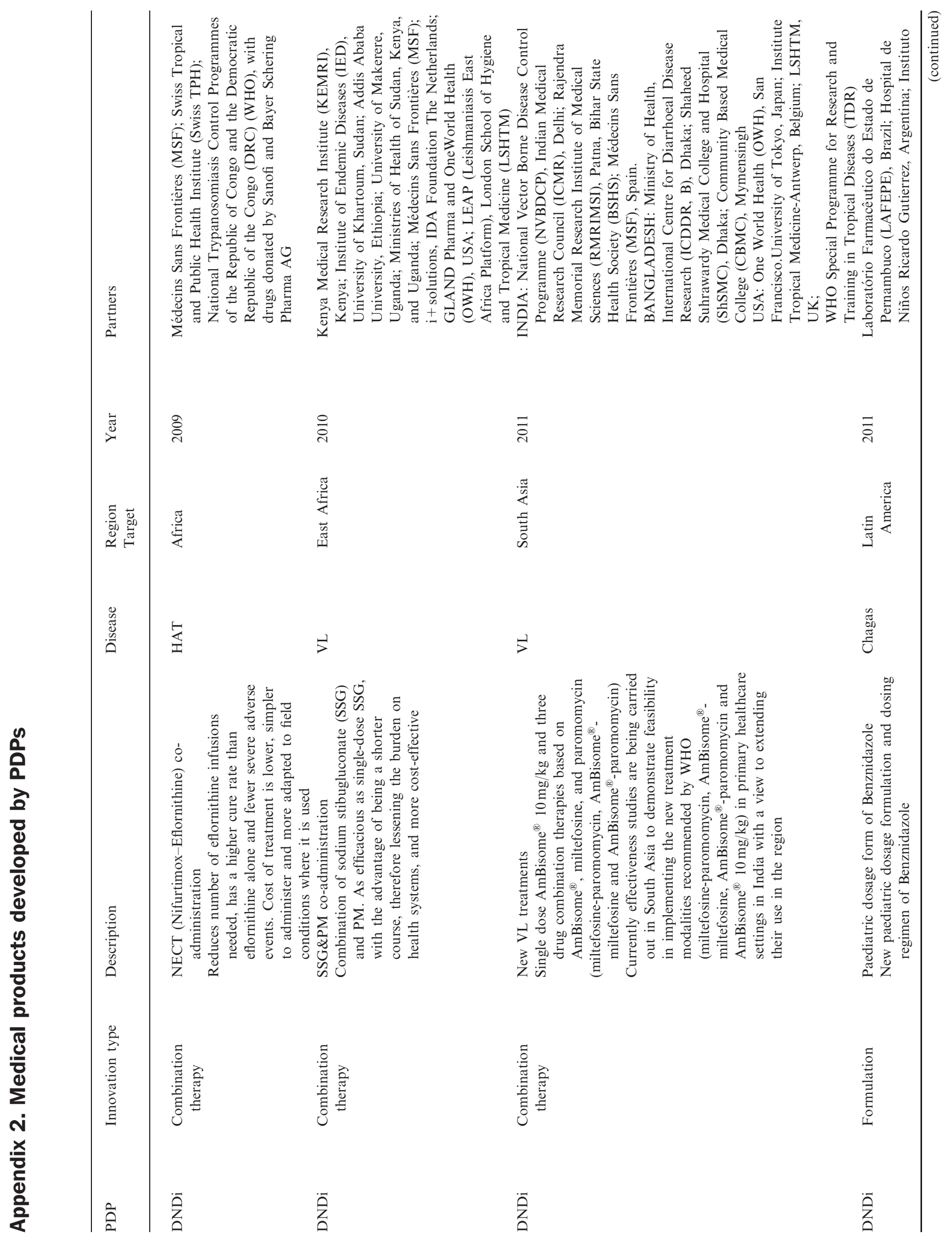




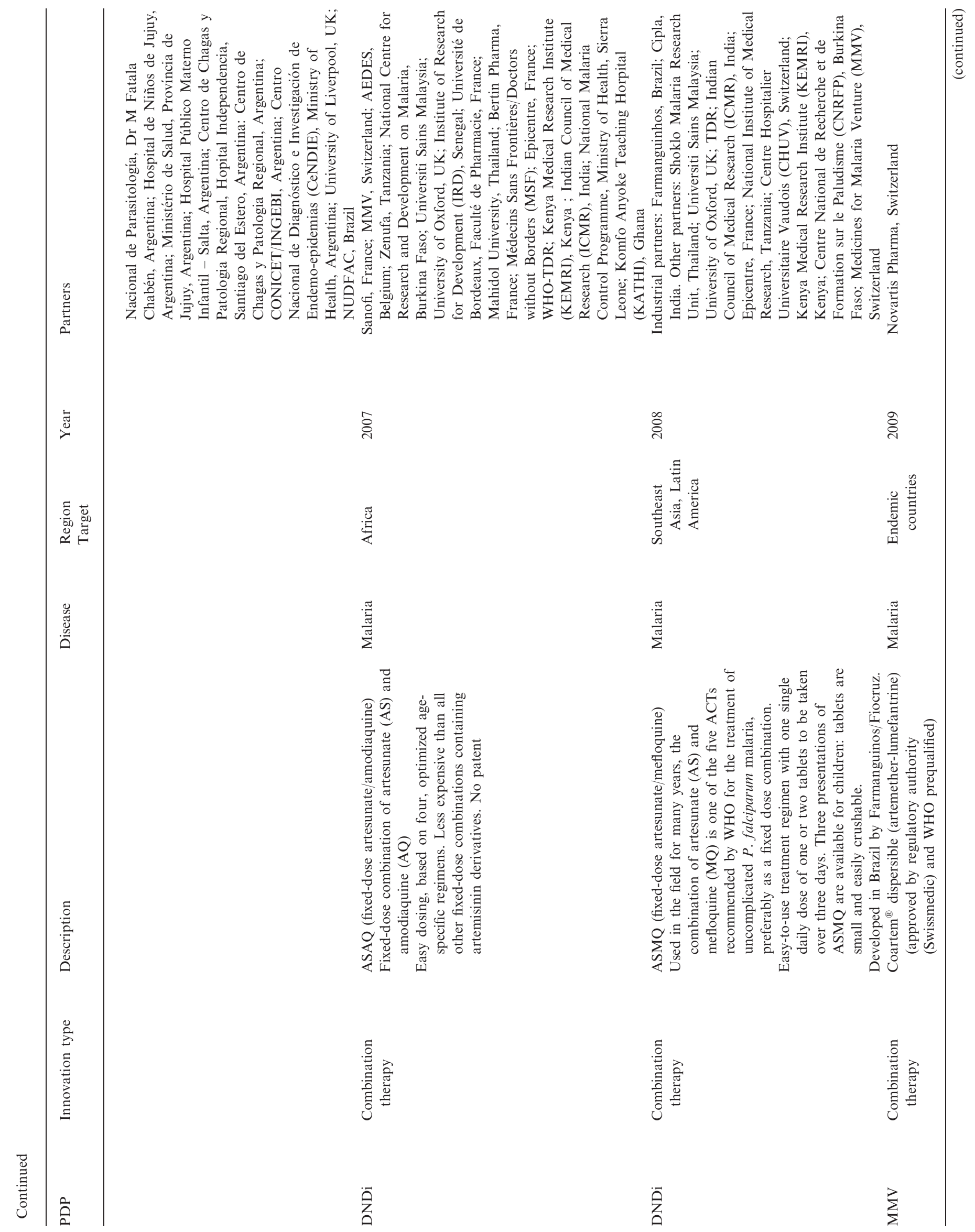




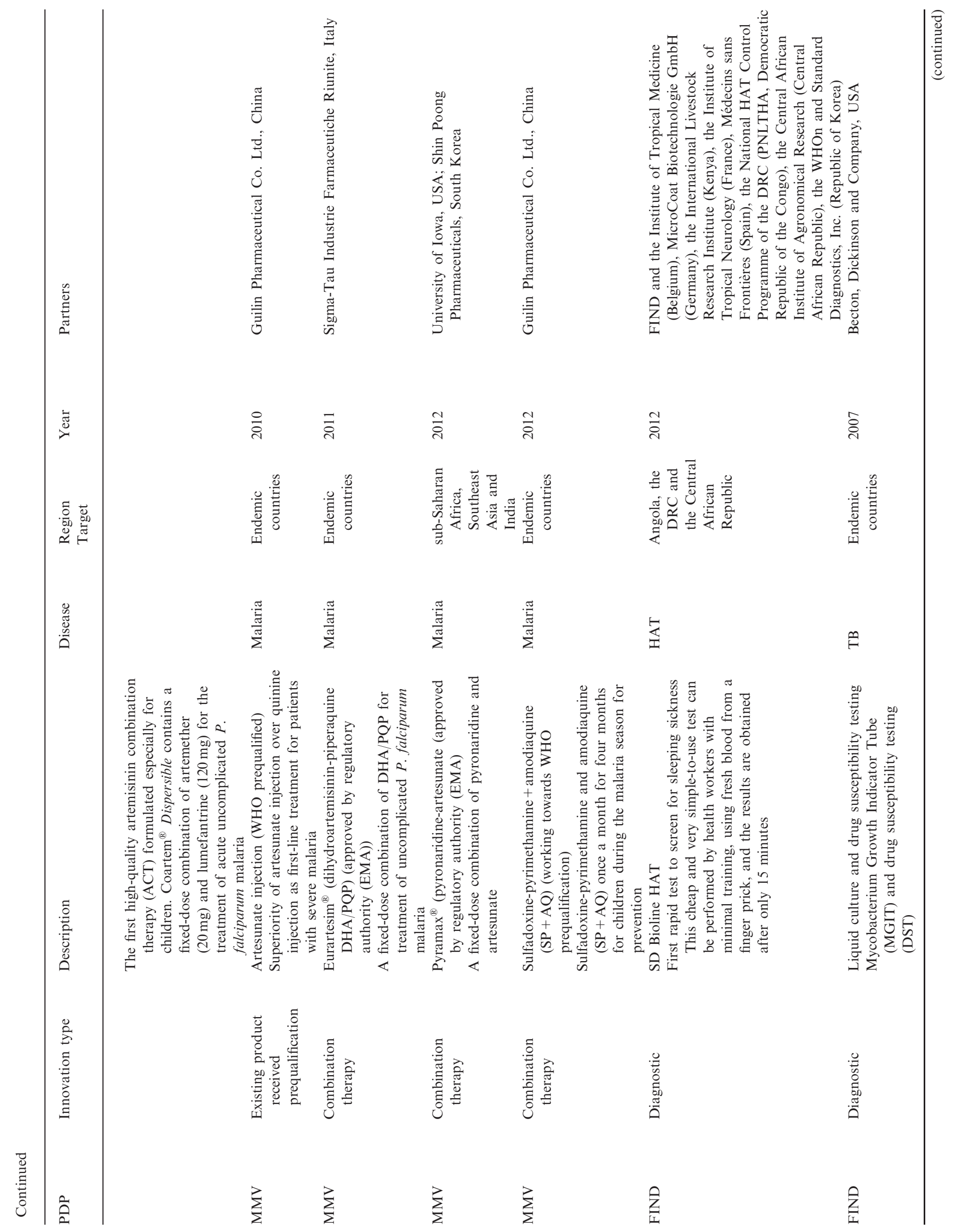



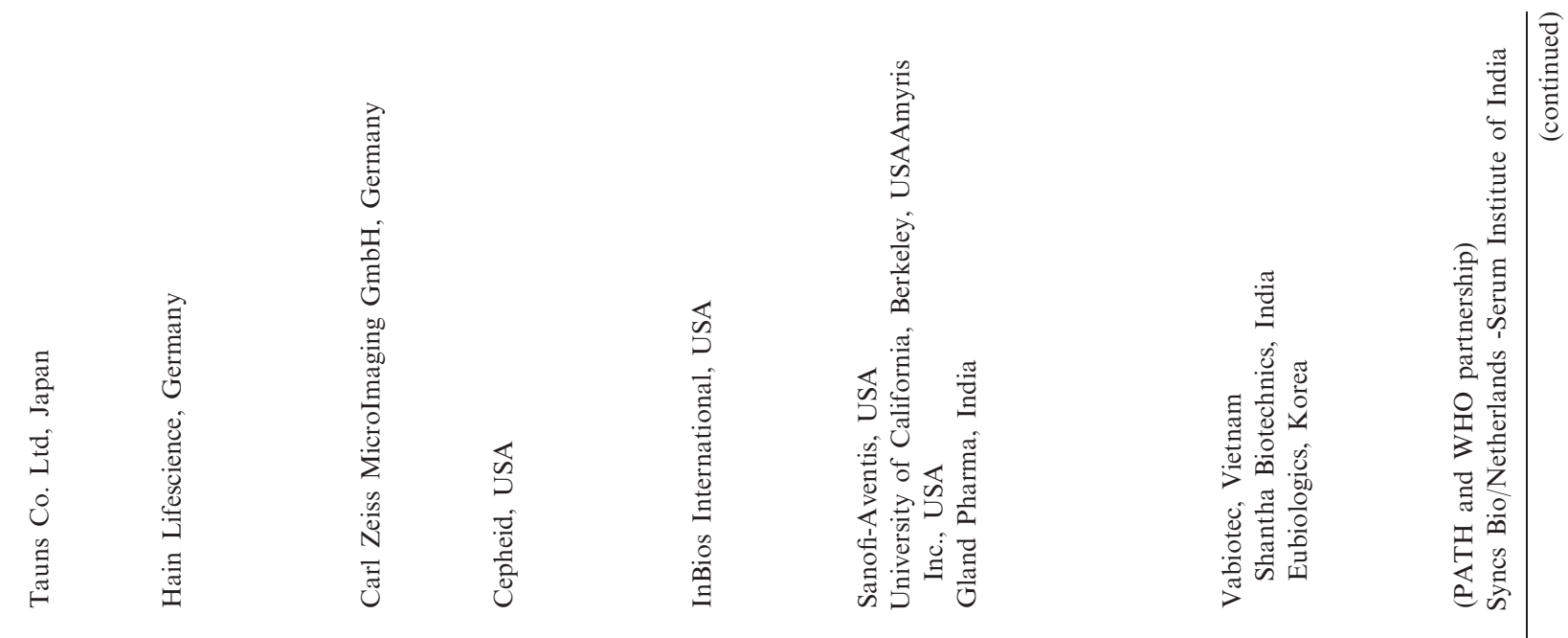

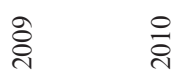

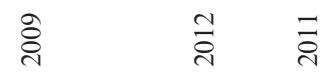

$\overline{\text { ㄱ. }}$

$\stackrel{ }{\stackrel{2}{*}}$

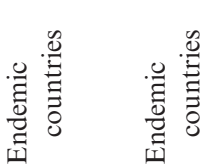

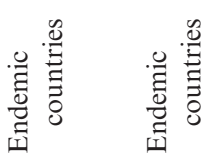
离

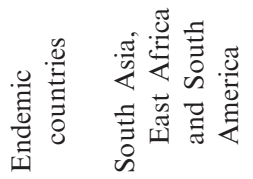

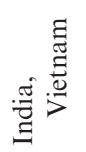
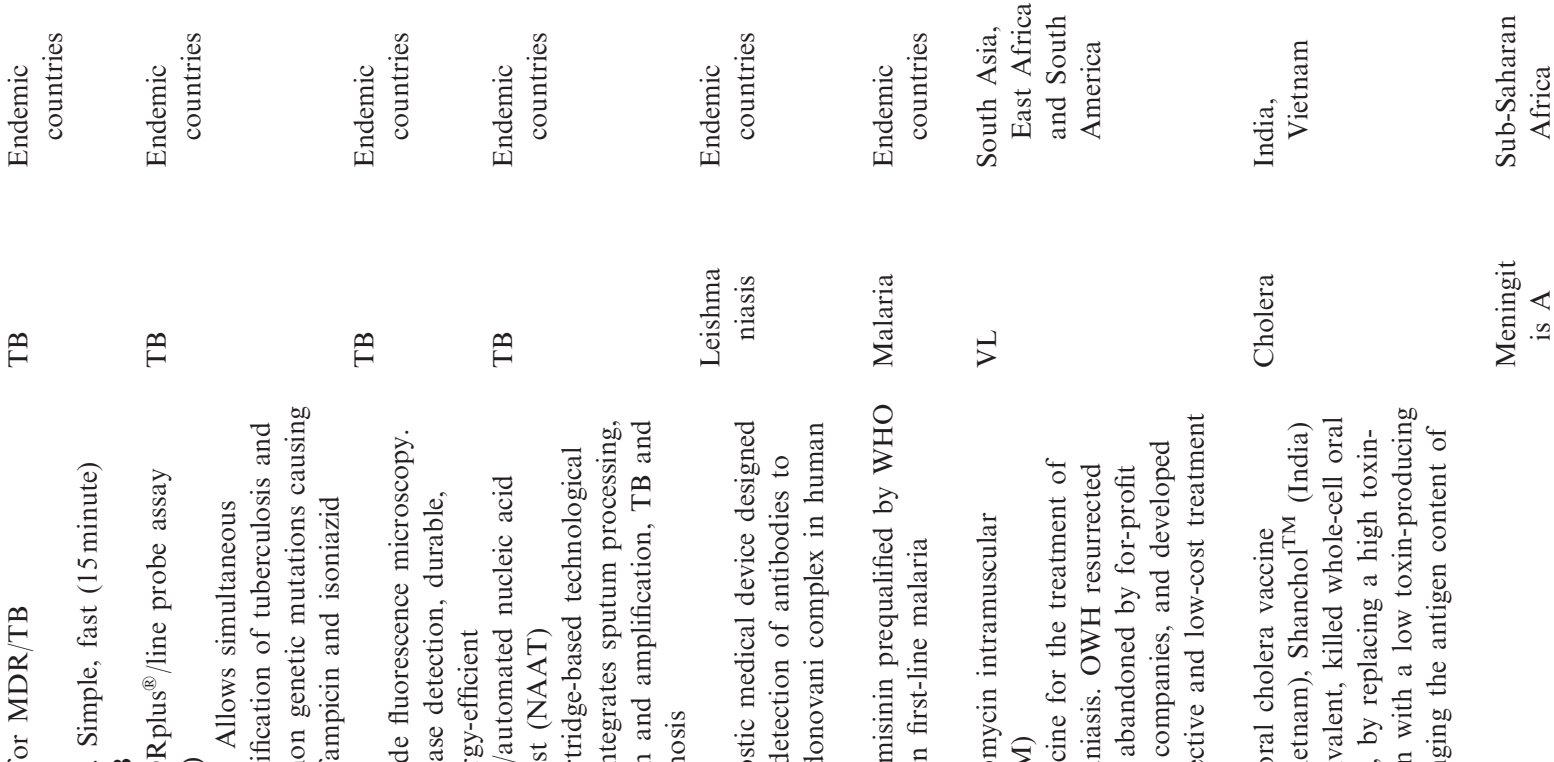

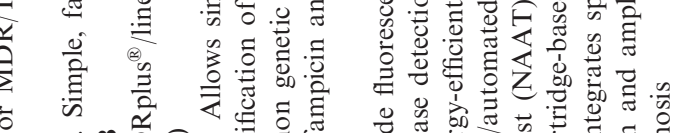

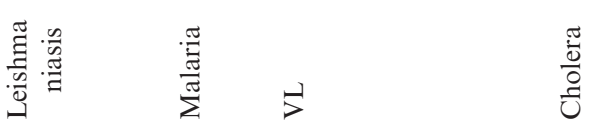

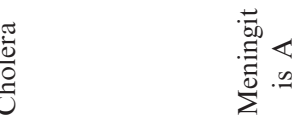

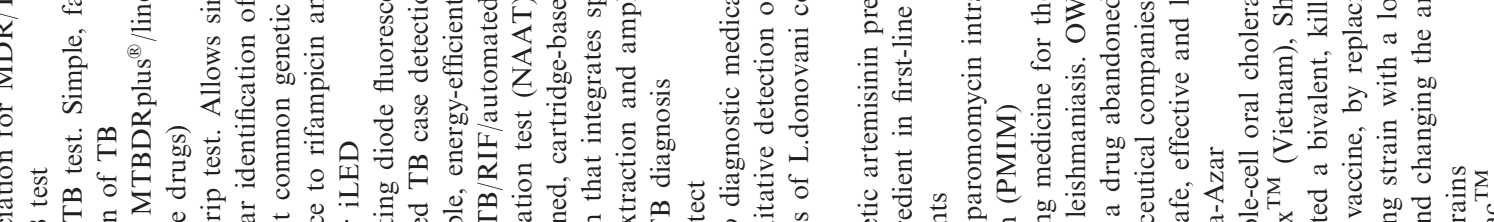

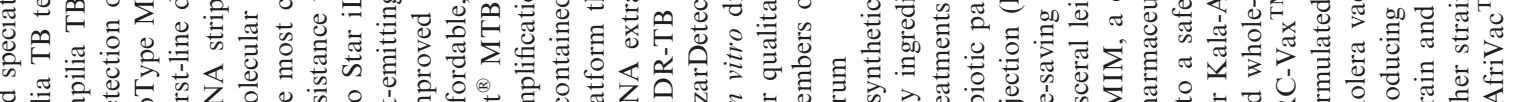

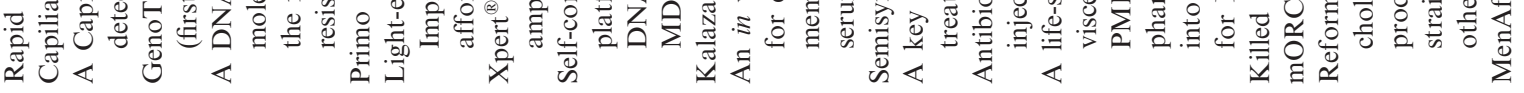

$\overrightarrow{\underline{n}}$

$\sum_{0.1}^{1} \quad \stackrel{0}{0}$

$\Sigma$ 


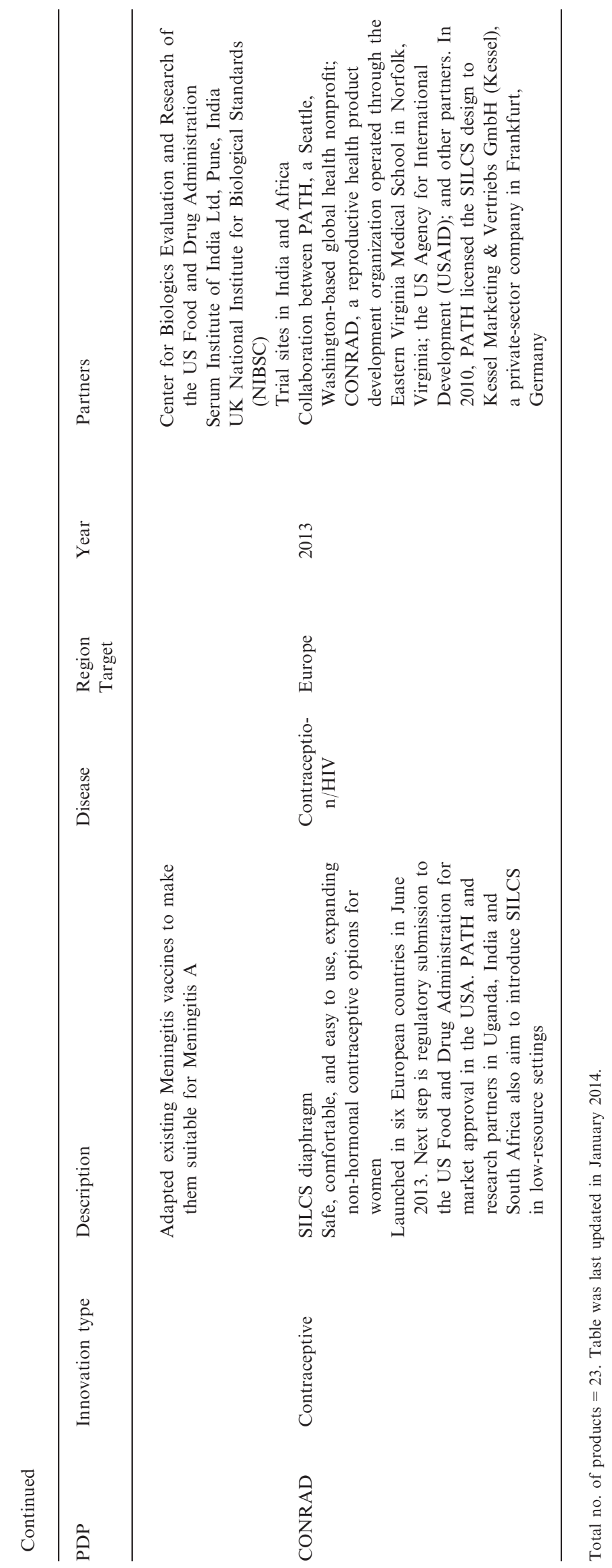

